$0,2 \pi-5$

LA-8747-MS

$85^{97}$

Sorption-Desorption Studies on Tuff

III. A Continuation of Studies with Samples

from Jackass Flats and Yucca Mountain, Nevada

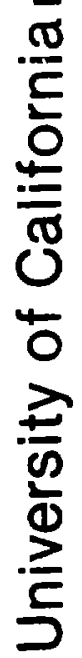

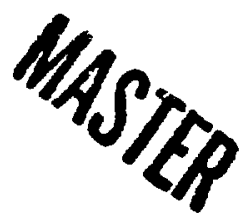

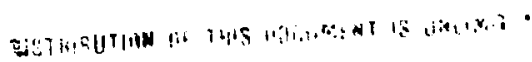

LOS ALAMO SCIENTIFIC LABORATORY

Post Office Box 1663 Los Alamos. New Mexico 87545 


\section{Sorption-Desorption Studies on Tuff}

\section{A Continuation of Studies with Samples}

\section{from Jackass Flats and Yucca Udountain, Nevada}
K. Wolfsborg
S. Maestas
R. D. Aguilar v
A. J. Mitchell
B. P. Bayhurst 、
W. R. Daniols
S. J. DoVillicrs
P. Q. Oliver
N. A. Raybold
B. R. Erdal
R. S. Rundberg
F. O. Lawrence
J. L. Thompion*
E. N. Vine

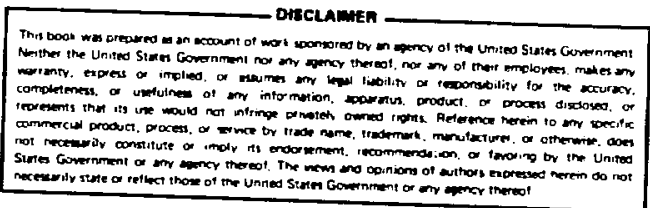

"Short-Term Visiting Staff Member. Idsho State University, Pocatello, ID 83200.

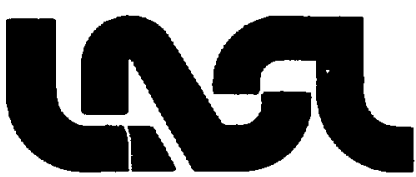

exrinurion ef rus cecument to 
TABLE OF CONTENTS

ABSTRACT . . . . . . . . . . . . . . . . . . . . . . . 1

EXECUTIVE SUMMARY . . . . . . . . . . . . . . . . . . . . 1

I. INTRODUCTION . . . . . . . . . . . . . . . . . . . . . 3

II. SORPTION OF STRONTIUM, CESIUM, BARIUM, CERIUM, AND EUROPIUM ON ADDITIONAL TUFF SAMPLES . . . . . . . . . . . . . . . . . . . . 6

III. SORPTION OF PLUTONIUM AND AMERICIUI -- NORMAL AND CONTROLLEDATMOSPHERE CONDITIONS ........ . . . . . . . . . . . . . . 7

A. Experimental . . . . . . . . . . . . . . . . . . . 7

B. Results and Conclusions . . . . . . . . . . . . . . . 11

IV. URANIUM(VI) SORPTION STUDIES . . . . . . . . . . . . . . . . . . . 21

V. COMPARISON OF BATCH STUDIES MADE UNDER ATMOSPHERIC AND CONTROLLEDATMOSPHERE CONDITIONS .. . . . . . . . . . . . . . . . . . . 21

A. Results and Observations . . . . . . . . . . . . . . . . 23

B. General Conclusions . . . . . . . . . . . . . . . . . . 25

VI. DEPENDENCE OF SORPTION ON SOLUTION-TO-SOLID RATIO . . . . . . . . . 25

VII. DEPENDENCE OF SORPTION ON ELEMENT CONCENTRATION -- ISOTHERMS . . . 26

A. Experimental . . . . . . . . . . . . . . . . . . . . . 29

B. Results and Conclusions . . . . . . . . . . . . . . . . 29

VIII. MIGRATION RATE STUDIES ON CRUSHED TUFF . . . . . . . . . . . . . . 41

A. Measurements . . . . . . . . . . . . . . . . . . . 41

B. Data Collection and Analysis . . . . . . . . . . . . . . . . 42

C. Results and Conclusions . . . . . . . . . . . . . . . . . . 43

IX. SORPTION MEASUREMENTS USING A CIRCULATING SYSTEM . . . . . . . . . 46

X. RADIONUCLIDE SORPTION AND TRANSPORT STUDIES WITH SOLID BOCK CORES . 47

A. ${ }^{85} \mathrm{Sr}$ in $\mathrm{YM}-22$ Tuff . . . . . . . . . . . . . . . . . 48

B. $241 \mathrm{Am}$ in YM-45 Tuff ....................... 49

C. $241 \mathrm{Am}$ in Climax Stock Granite. . . . . . . . . . . . . . . . . 50

D. Encased Cores . . . . . . . . . . . . . . . . . . . . . 52

XI. REDOX POTENTIAL OF GROUNDWATERS . . . . . . . . . . . . . . . . . . 55

XII . MATERIALS CHARACTERIZATION . . . . . . . . . . . . . . . . . 56

A. Water Composition . . . . . . . . . . . . . . . . . . . 57

B. Determination of Fe(II) in Silicate Rocks........... . 59

C. Determination of $\mathrm{Fe}(\mathrm{II})$ in Groundwater . . . . . . . . . . . . 60

D. Emission Spectrometric Analysis of Groundwaters . . . . . . . . 61

XIII. COMPARISON OF SORPTION RATIOS FROM BATCH, CIRCULATING-SYSTEY, AND COLURN METHODS . . . . . . . . . . . . . . . . . . . . 61

XIV. CONCLUSIONS . . . . . . . . . . . . . . . . . . . . . . 62

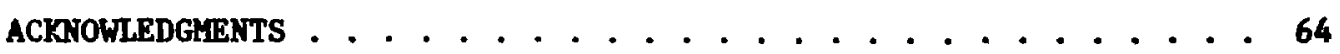

REFERENCES ............................ 65 
SORPTION-DESORPTION STUDIES ON TUFF

III. A Continuation of Studies with Samples

from Jackass Flats and Yucca Mountain, Nevada

K. Wolfsberg, R. D. Aguilar, B. P. Bayhurst, W. R. Daniels,

S. J. DeVilliers, B. R. Erdal, F. O. Lawrence, S. Maestas,

A. J. Mitche1l, P. Q. Oliver, N. A. Raybold, R. S. Rundberg,

J. L. Thompson, and E. N. Vine

\section{ABSTRACT}

This report is the third in a series of reports describing studies of sorption and migration of radionuclides in tuff. The investigations were extended to lithologies of tuff not previously studied. Continuing experiments with uranium, plutonium, and americium are described. The dependence of sorption on the concentration of the sorbing element and on the solution-tosolid ratio was investigated for a number of nuclides and two lithologies. A circulating system was designed for measuring sorption ratios. Values obtained from this system, batch measurements, and colum elutions are compared. Progress on measuring and controlling Eh is describea.

\section{EXECUTIVE SUMAARY}

This report is the third in a series presenting the Los Alamos National Laboratory's investigations on the sorptive properties of tuff. If tuff is to be considered as a nuclear waste repository medium, then it is necessary to understand transport of radionuclides through tuff and retardation mechanisus to perfora safety assessments. It is also necessary to build up a data base of sorptive properties for the specific location of a tuff repository presently being considered. 
In FY 1981, our sorptive studies were extended to tuff lithologies not previously studied. Data presented in this report indicate that the sorptive behavior of the zeolite analcime is not like that of clinoptilolite or heulandite; rather, the behavior seems similar to that of devitrified tuff.

somewhat higher sorption ratios for americium and plutonium were obtained for tuff samples from the Yucca Mountain hole (UE25a\#1) than for those from the Jackass Flats hole (J-13). However, the differences may be due to an improved phaseseparation technique.

Small sorption and desorption ratios for uranium(VI) have been measured for Yucca Mountain tuffs; the desorption ratios are somewhat larger than the sorption ratios. Sorption ratios obtained with crushed-tuff columns are smaller than those with batch measurements.

The variation of sorption ratio with concentration of sorbing element was studied for strontium, cesium, barium, and europium between $\sim 10^{-8}$ and $\sim 10^{-3} \mathrm{M}$. The largest variations from ideal behavior are at the highest concentrations, perhaps because of saturation of sorption sites or precipitation. The data are discussed in terms of deviation from linear isotherms.

The results of sorptive studies in air and in a nitrogen atmosphere ( $\leqq 0.2 \mathrm{ppm}$ oxygen, $\leqq 20 \mathrm{ppm}$ carbon dioxide) are compared. The largest differences are found for technetium, uranium, and plutonium, which sorb more strongly, somewhat dependent on the mineralogy of the tuff, in the nitrogen atmosphere.

When the solution-to-solid ratio in batch measurements was changed from 5:1 to $30: 1$, only smal1 (or no) increases in sorption of strontium and cesium were noted in most experiments. Larger increases, by factors of $\sim 5$, were observed for sorption of bariun, cerium, and europium.

A circulating system has given sorption ratios that are quite comparable with those from crushed columns. In addition, this methodology does not appear to show as much contact-time dependence for sorption as the batch method. Sorption ratios from batch, circulating-system, and column experiments are compared. 
The methodology for studying transport through whole cores has been improved by use of encasing technigues. New experiments are under way.

Control of redox potentials in the laboratory may involve the use of a poteriostat to achieve a desired redox condition and moderators to maintain the condition. Initial efforts to develop such moderators are reported. Redox potentials are measured with electrodes or may be obtained from analysis of redox pairs such as $\mathrm{Fe}(I I) / \mathrm{Fe}(I I I)$.

Except for poor sorption of anions (also typical for other media), tuff has excellent sorptive properties. An understanding of sorption and migration mechanisms is being obtained.

\section{INTRODUCTION}

The Los Alamos National Laboratory has been studying the sorptive behavior of tuff and transport of radionuclides through tuff as part of the Nevada Nuclear Waste Storage Investigations (NNWSI). The study has been partly generic in nature (to understand the sorptive behavior of tuff as a function of many variables) and partly site specific (to obtain data for a possible repository site in tuff). It is necessary to have an understanding of the mechanisms of transport and retardation of radionuclides through tuff, as well as to have a data base of sorptive properties to perform the required safety assessment dealing with possible releases from a repository in tuff. Previous reports in this series are Refs. 1 and 2 . The work has also been summarized in Refs. 3-7.

When the work was initiated, the only appropriate tuff samples for this study were from Drill Hole (later We11) J-13 (Ref. 8) in western Jackass Flats at the Nevada Test Site (NTS). As the NWWSI identified Yucca Mountain as a possible repository location and undertook an exploratory drilling program, samples from Hole UE25a-1 (Ref. 9) became available. Studies presenter so far have been with tuff cores from these two holes. Hork is now under way with samples from Hole USW-G1 on Yucca Mountain.

Tuffaceous groundwater for these studies has so far been obtained from Well J-13 (Ref. 10) in Jackass Flats; none has been available from holes on Yucca Mountain. To better simulate water in contact with the rocks under investigation, the water from Well $\mathrm{J}-13$ is pretreated with the particular rock. 
Analyses of the water before and after such treatment have indicated only minor changes in composition.

Perhaps a more critical problem is simulation of the redox conditions that exist in the actual rock-groundwater systems. If the underground conditions are reducing, as is postulated for many deep geologic systems, then the sorptive behavior of elements such as technetium, uranium, neptunium, and plutonium will be different than under the normal, mildly oxidizing conditions in air. In their lower oxidation states, these elements are generally more insoluble or sorb better on geologic media and, consequently, should be retarded better than in the higher states. However, at the present time, we do not have a definitive description of the actual redox conditions in the tuff formations under investigation or of conditions that wight be in possible release scenarios. Preliminary observations of the alteration features of the mafic minerals in zones of the Bedded Tuff of Calico Hills and Prow Pass members of the Crater Flat Tuff suggest possible oxidizing conditions, at least at the time that alteration was occurring (R. G. Warren, Los Alamos, personal communication, December 1980). Our observations ${ }^{11}$ of the dissolvedcxygen content of water pumped from the J-13 well through a flowing cell at the surface also suggests oxidizing conditions. Independent work by the U. S. Geological Survey (USGS) has also shown that there are significant concentrations of dissolved oxygen in water from tuffaceous wells ( $\mathrm{J}-12$ and $\mathrm{J}-13$ ), as well as in some other deep water ( $\mathrm{I}$. J. Winograd and F. N. Robertson, USGS, personal communication, December 1980). However, contact of crushed tuff with groundwater under a controlled atmosphere $(\$ 0.2$ ppm oxygen, $\leqq 20 \mathrm{ppw}$ carbon dioxide; Sec. XI) gave apparently negative Eh values. The crushing may have exposed previously unexposed minerals. At this time, we are conducting investigations under both atmospheric and oxygen-free conditions and are planning to do experiments under controlled Eh conditions.

In Ref. 6 the variation of sorptive properties with mineralogy is evaluated. A rough relationship between sorptive properties and mineralogy for two categories of tuff, zeolitized (containing clinoptilolite snd/or heulandite) and devitrified (containing only quartz, cristobalite, and/or feldspar), was identified. However, dependence of sorption on other minerals such as analcime, clays, and glasses was not known. Sorption on alteration ainerals in fractures also remins to be studied. 
Also in Ref. 6 we noted that sorption ratios obtained from dynamic experiments (crushed-tuff column elutions) were in reasonable agreement with those from static (batch) measurenents, but usually a factor of 2 to 3 lower. This suggests that transport could occur somewhat faster than predicted from batch measurements alone. It was reported that some columns do not exhibit ideal ion-exchange column behavior with elution of elements in peaks, but rather show a slow, continuous elution. This indicates that simple "K" concepts of retardation in transport models may not be adequate. ${ }^{6}$ other retardation mechanisms such as precipitation, irreversible sorption, diffusion into the solid, colloid transport, and fixation must be considered. Studies of combined porous and fracture flow through solids are just beginning.

In this report we describe our efforts of the past year. Sorptive studies have been extended to include tuffs of different mineralogies. We summarize comparisons of studies conductio in air and in a nitrogen atmosphere. We investigated dependence of sorption on the solution-to-solid ratio and on the concentration of the sorbing element (isotherm studies). A circulating system was used as an alternative to the mechanical shaking of rock-water mixtures in the batch experiments, and the results of the two methods are compared. A new method of conducting experiments with whole or fractured cores was developed. Materials characterization is continuing. In particular we are attempting to describe the redox potential of the systems by means of $\mathrm{Fe}$ (II)/Fe(III) analyses and electrode measurements. We are developing ways of controlling the Eh of the systems.

The origin of the tuff samples studied and their mineralogic composition have been detailed elsewhere $1,2,6,8,9,12$ or are given in this report. The prefix JA- indicates the sample was obtained from Hole J-13; the prefix Yirfrom Hole UE25a-1. The following descriptions summarize the abundant minerals observed in the samples studied for sorptive properties. Samples that contain the zeolites clinoptilolite or heulandite $(>15 \%)$ plus quartz, cristobalite, and/or feldspars include those from cores YM-38, YM-42, YM-48, and YM-49. Tuffs that are generally known as devitrified tuffs and that contain predominantly quartz, cristobalite, and/or feldspars include those from cores JA-32, YM-22, YM-45, YM-46, and YM-54. Samples JA-8, JA-18, and YM-5 contain fresh

\footnotetext{
*pal has been identified in Prow Pass and Bullfrog samples. X-ray diffraction patterns of opal and cristobalite are indistinguishable (R. G. Warren, Los Alamos, personal commication, Decerber, 1980).
} 
glass; in addition sample JA-8 contains clay (montmorillonite), and sample JA-18, clinoptilolite. Samples JA-26 and JA-28 contain the zeolite analcime, quartz, and feldspars. Sample YM-30 is a devitrified tuff with clinoptilolite $(\sim 15 \%)$ in fractures.

The granite used in some studies came from the mine dump area of the Piledriver tunnel. 13

We use the sorption ratio $R_{d}$ as a measure of sorption as a function of many parameters. It is defined as

$$
R_{d}=\frac{\text { activity in solid phase per unit mass of solid }}{\text { activity in solution per unit volume of solution }} .
$$

Many authors refer to this ratio as the distribution coefficient $K_{d}$. We prefer not to use this term, which implies equilibrium, because we know that reversible equilibrium is usually not attained. If equilibrium is attained, then $k_{d}$ is related to a retardation factor $R_{f}$ in a uniform flowing system by

$$
R_{f}=K_{d}(\rho / \varepsilon)+1,
$$

where $\rho$ is the bulk density and $\varepsilon$ is the porosity.

II. SORPTION OF STRONTIUM, CESIUM, BARIUM, CERIUM, AND EUROPIUM ON ADDITIONAL TUFF SAMPLES

Sorption measurements of strontium, cetium, barium, cerium, and europium on a group of six Yucca Mountain tuff samples from Hole UE25a-1 at the NTS were reported previously. ${ }^{2}$ Those measurements indicate, particularly for strontium, cesium, and barium, that the presence of zeolites is important for high sorption ratios. In order to expand those studies and, hopefully, to better relate them to measurements made earlier ${ }^{1}$ on tuff samples from Hole $\mathrm{J}-13$, four additional Yucca Mountain tuffs were studied by the batch technique under normal atmospheric conditions. For comparison, measurements with sample JA-18 were repeated.

The YM-30 sample is a fractured, densely welded, devitrified tuff containing zeolites. The YM-5 sample is a fresh (glassy) nonwelded tuff without zeolites. The YM-42 sample is an immature sandstone with a clay matrix; and the YM-46 sample, a devitrified, densely welded, vitric-crystal tuff, has heavy iron staining but no zeolites. Three tuffs from Hole J-13 were also 
studied: JA-8, JA-26, and JA-28. Analysis by $x$-ray diffraction ( $J$. R. Smyth, Los Alamos, personal communication, April 1980) indicates that sample JA-8 is $\sim 25$ to $50 \%$ montmorillonite, 10 to $20 \%$ cristobalite, and 25 to $50 \%$ glass. The JA-26 and JA-28 samples are primarily analcime, quartz, and alkali feldspar. In addition, sample JA-28 contains 2 to $5 \%$ illite/muscovite.

Sorption data and average values are given in Table $I$. Data for 3week contact times are shown for samples JA-26, JA-28, and JA-8. Results from additional experiments will be available when counting and data analysis have been completed.

The data in Table I generally confirm the sorption-mineralogy correlations noted previously. ${ }^{5,6}$ It is interesting that cores JA-26 and JA-28, which contain analcime in addition to quartz and feldspar, have sorption ratios $\left(R_{d}\right)$ very similar to those of devitrified, nonzeolitized tuffs. Apparently, the sorptive behavior of analcime is quite different from that of clinoptilolite and heulandite.

III. SORPTION OF PLUTONIUM AND AMERICIUM -- NORMAL AND CONTROLLED-ATMOSPHERE CONDITIONS

\section{A. Experimental}

Measurement of the sorptive behavior of plutonium and americium on Yucca Mountain tuff (cores $\mathrm{YM}-22, \mathrm{YM}-38$, and $\mathrm{YM}-54$ ) involved geologic materials and groundwaters described earlier. ${ }^{2}$ The equipment used to achieve controlledatmosphere conditions (nitrogen, $\leqq 0.2$ ppm oxygen, $\leqq 20$ ppm carbon dioxide), the calculational methods, and the experimental techniques have been described. ${ }^{2}$ For the current studies tracers were dried in air at room temperature. After dissolution of the tracers in the appropriate groundwater under the desired atmosphere, the traced feed solutions were centrifuged and passed through $0.4-\mu \mathrm{m}$ and then $0.05-\mu \mathrm{m}$ Nuclepore filters. All contacts were at $32^{\circ} \mathrm{C}$ for controlled-atmosphere and $22^{\circ} \mathrm{C}$ for atmospheric experiments. Contact times for sorption were 3,6 , and 12 weeks with the corresponding desorptions being 12,9 , and 3 weeks. The final separation of phases after contact was accomplished by three consecutive centrifugings at $12000 \mathrm{rpm}(28009 \mathrm{~g})$ for 1,1 , and 2 hours, respectively. Transfers were performed by pipetting. The final centrifuged solutions were aliquoted for counting and then passed through $0.05-\mu \mathrm{m}$ Nuclepore filters. They were then aliquoted again for comparison 
TABLE I

SORPTION RATIOS FOR ADDITIONAL TUFF SAMPLES ${ }^{a, b}$

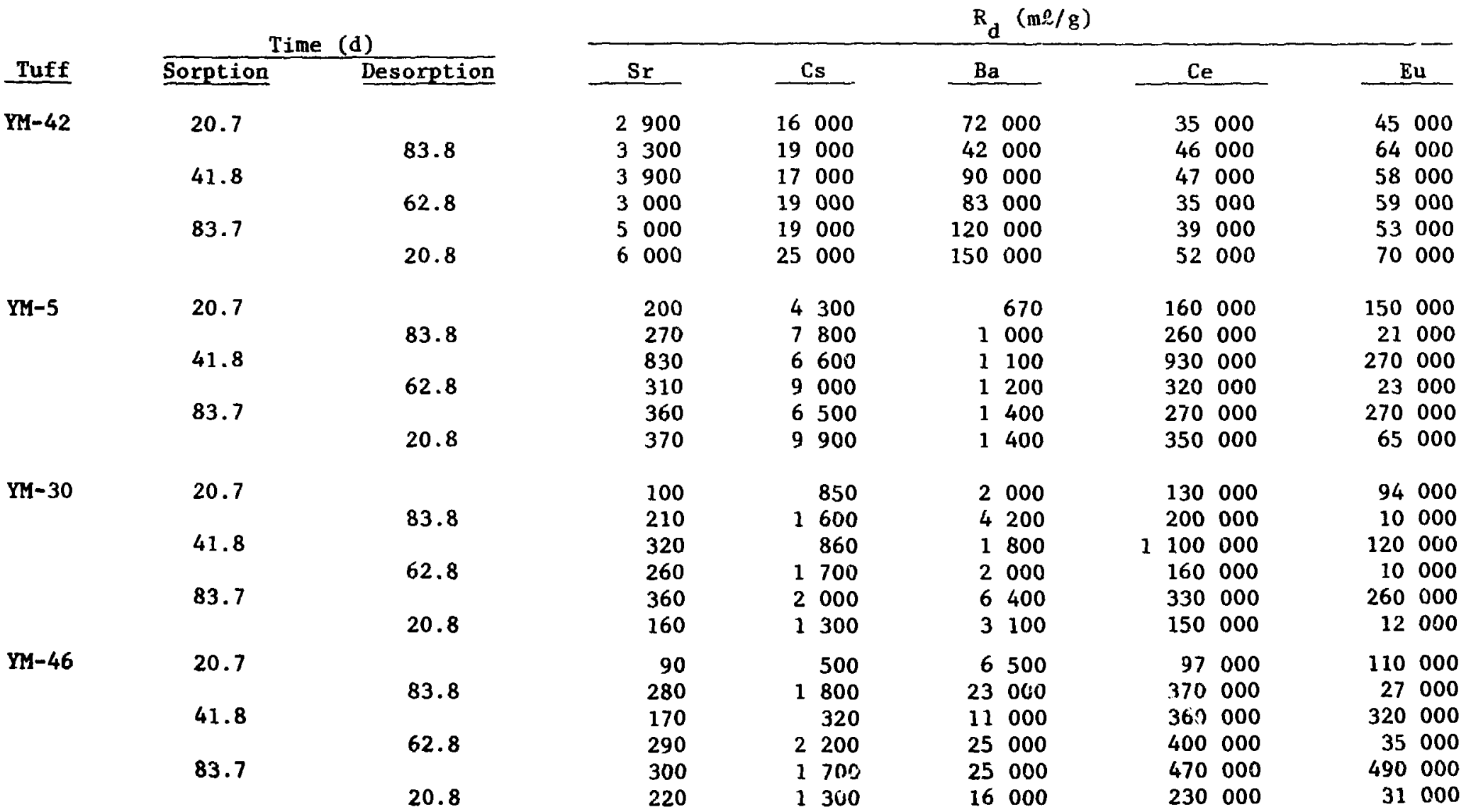


TABLE I (cont)

SORPTION RATIOS FOR ADDITIONAL TUFF SAMPLES

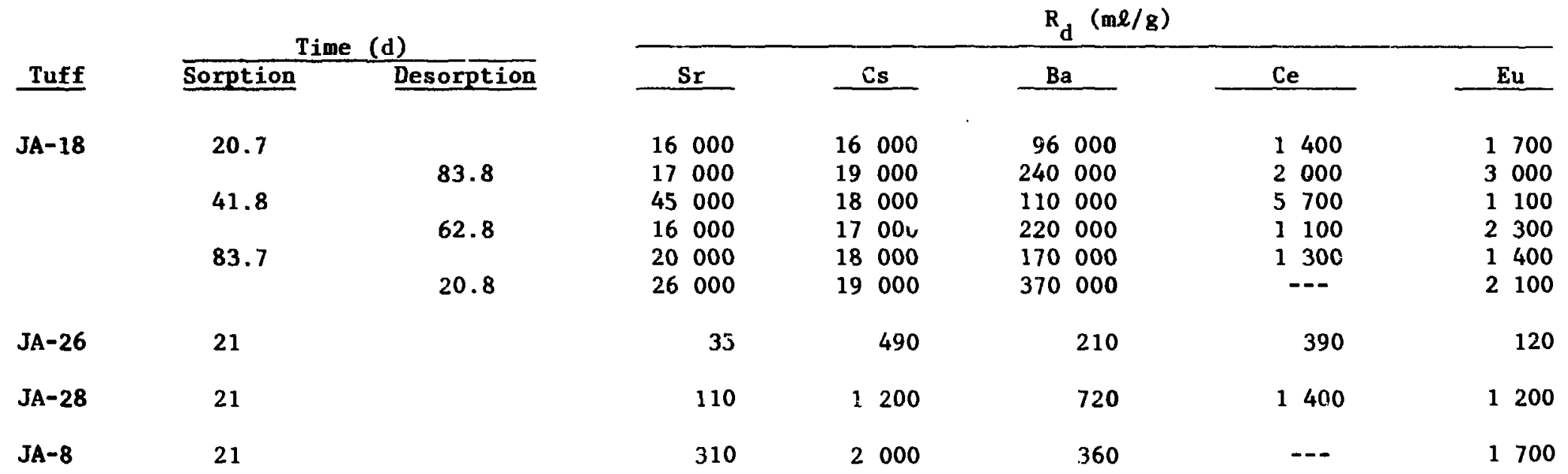


TABLE I (cont)

SORPTION RATIOS FOR ADDITIONAL TUFF SAMPLES

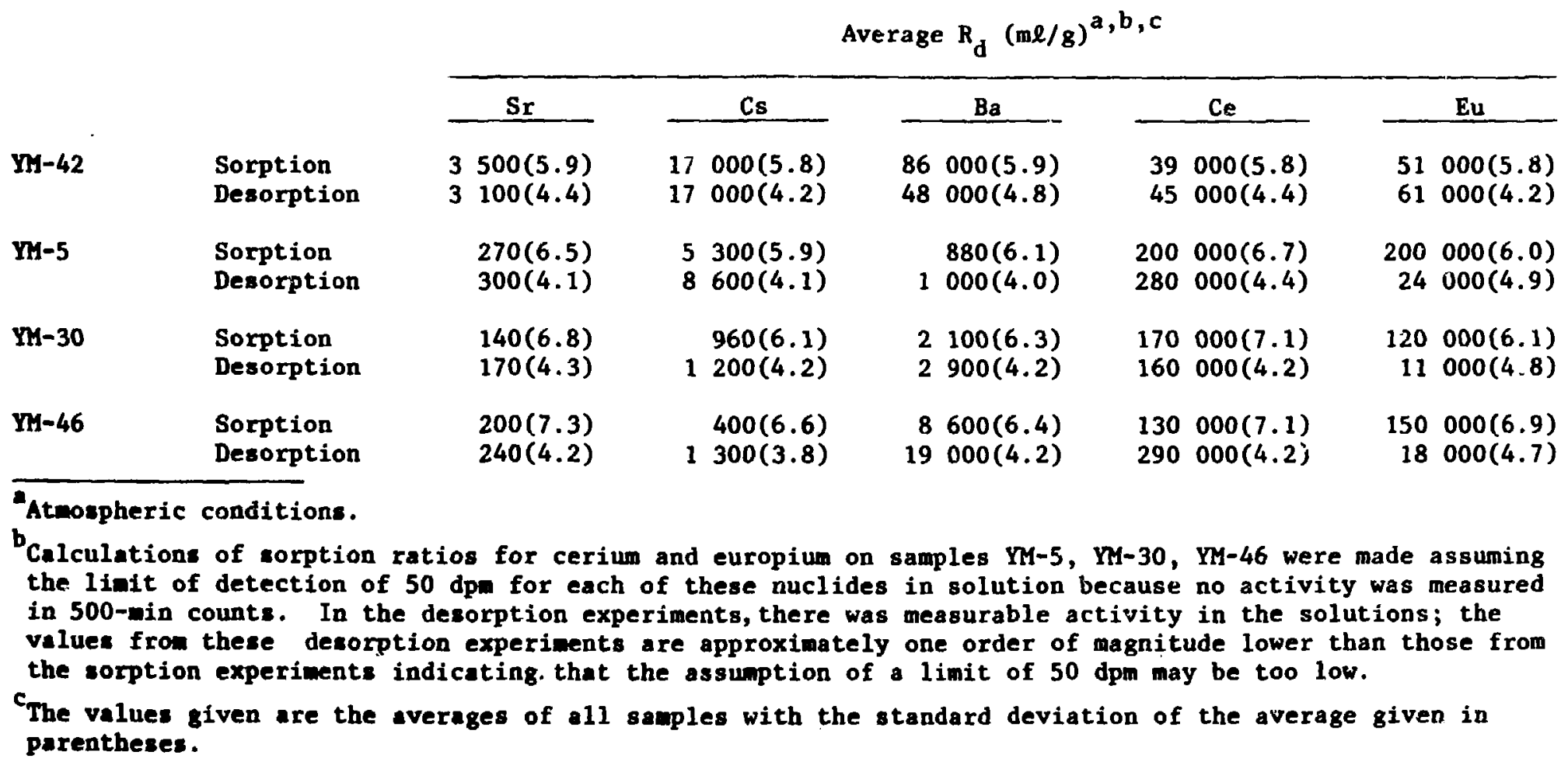


with the results from unfiltered solutions. Solid phases were also gama counted.

\section{B. Results and Conclusions}

The results for the batch measurements of the sorptive behavior of ${ }^{241} \mathrm{Am}$ and ${ }^{237} \mathrm{Pu}$ under both atmospheric and controlled-atmosphere conditions are given in Tables II-V. The ${ }^{237} \mathrm{Pu}$ results suffer somewhat from the low concentrations of tracer remaining in solution after contact. This is primarily a consequence of the small amount of ${ }^{237} \mathrm{Pu}$ available, its short half-life, and the generally large sorption ratios. In several cases only linits on the $R_{d}$ values could be set. It was previously reported that the current centrifuging procedure gave plutoniun, but not americium, solutions from which no additional tracer was removed by filtering. In general, these observations have been confirmed by additional measurements; ${ }^{14}$ however, some solutions that have extremely low concentrations of plutonium apparently lose plutoniun when filtered (Tables II and III). This effect could be due to removal of some minute amounts of solid phase remaining in the aqueous phase. As stated previously, if the results for unfiltered solutions are in error, it is probably in the conservative direction (that is, too low $B_{d}$ values), so data from these have been used to calculate the average sorption ratio values given in Table VI. These data have been averaged over three contact times and two particle sizes.

The current results for normal atmospheric conditions tend to give somewhat higher $R_{d}$ values for unfiltered solutions than thoie reported previously. ${ }^{1,2}$ This is reasonable because the improved phase-separation technique removes essentially all solid material from the aqueons phase. The current data are, therefore, considered to be more accurate. Current data for filtered solutions are consistent with earlier results; in both cases anericium apparently sorbed on the filter membrane.

The following observations can be made. The $R_{d}$ values for both the sorption and desorption of plutoniu for all three tuffs tend to be higher under controlled-atmosphere conditions than in air. Such a change with a change in atmosphere is not surprising considering the known ${ }^{2}$ speciation effects of plutonium; the oxidation states wight even differ under the two sets of conditions. The situation with americium is not consistent. For the devitrified YM-22 tuff, anericium has lower $R_{d}$ values for both sorption and 
TABLE II

${ }^{237}$ Pu SORPTION RATIOS, ATMOSPHERIC CONDITIONS ${ }^{a}$

\begin{tabular}{|c|c|c|c|c|c|c|c|c|}
\hline \multirow[b]{2}{*}{ Core } & \multirow{2}{*}{$\begin{array}{l}\text { Fraction } \\
(\mu \mathrm{n}) \\
\end{array}$} & \multirow{2}{*}{$\begin{array}{l}\text { Approximate } \\
\text { Pu Molarity } \\
\end{array}$} & \multicolumn{2}{|c|}{ Time (d) } & \multicolumn{2}{|c|}{$R_{d}(m \ell / g)$} & \multicolumn{2}{|c|}{ pH } \\
\hline & & & Sorption & Desorption & Unfiltered & Filtered & Initial & Final \\
\hline \multirow[t]{10}{*}{ YM-22 } & $<75$ & $4.5 \times 10^{-12}$ & 20.7 & & 130 & 140 & 8.62 & 7.55 \\
\hline & & & & 88.9 & 1400 & 1500 & 8.60 & 8.42 \\
\hline & & & 41.7 & & 210 & 200 & 8.62 & 7.58 \\
\hline & & & & 64.0 & 1300 & 1400 & 7.75 & 8.24 \\
\hline & & & 83.7 & & 280 & 280 & 8.62 & 8.38 \\
\hline & $75-500$ & & & 20.9 & 1900 & $18 \mathrm{~J}$ & 7.80 & 8.32 \\
\hline & $15-500$ & & 20.7 & 000 & 37 & 41 & 8.62 & 7.56 \\
\hline & & & 41.7 & 88.9 & 1300 & 1900 & $\begin{array}{l}8.60 \\
8.62\end{array}$ & $\begin{array}{l}8.45 \\
7.66\end{array}$ \\
\hline & & & & 64.0 & 1300 & 1300 & 7.75 & 8.39 \\
\hline & & & 83.7 & & 99 & 100 & 8.62 & 8.38 \\
\hline \multirow{11}{*}{ YM-38 } & $<75$ & $3.6 \times 10^{-12}$ & & 20.9 & 1400 & 1400 & 7.80 & 8.36 \\
\hline & & $3.6 \times 10$ & 20.7 & 000 & 130 & 140 & 8.56 & 7.40 \\
\hline & & & 41.7 & 88.9 & $\begin{array}{r}1700 \\
320\end{array}$ & $\begin{array}{r}2300 \\
340\end{array}$ & $\begin{array}{l}8.52 \\
8.56\end{array}$ & $\begin{array}{l}8.45 \\
7.65\end{array}$ \\
\hline & & & & 64.0 & 2200 & 3000 & 7.82 & 8.38 \\
\hline & & & 83.6 & & 650 & 740 & 8.56 & 8.34 \\
\hline & $75-500$ & & & 20.9 & 4300 & 7400 & 7.17 & 8.36 \\
\hline & & & 20.7 & & 58 & 60 & 8.56 & 7.59 \\
\hline & & & 41.7 & 88.9 & 1100 & 1200 & $\begin{array}{l}8.52 \\
8.56\end{array}$ & 8.46 \\
\hline & & & & 64.0 & 1000 & 1.100 & $\begin{array}{l}8.36 \\
7.82\end{array}$ & $\begin{array}{l}7.67 \\
8.41\end{array}$ \\
\hline & & & 83.6 & & 240 & 240 & 8.56 & 8.38 \\
\hline & & & & 20.9 & 1800 & 3100 & 7.17 & 8.37 \\
\hline
\end{tabular}


TABLE II (cont)

${ }^{237}$ PU SORPTION RATIOS, ATMOSPHERIC CONDITIONS ${ }^{a}$

\begin{tabular}{|c|c|c|c|c|c|c|c|c|}
\hline \multirow[b]{2}{*}{ Core } & \multirow{2}{*}{$\begin{array}{l}\text { Fraction } \\
(\mu)) \\
\end{array}$} & \multirow{2}{*}{$\begin{array}{l}\text { Approximate } \\
\text { Pu Molarity }\end{array}$} & \multicolumn{2}{|c|}{ Time(d) } & \multicolumn{2}{|c|}{$R_{d}(m \ell / 8)$} & \multicolumn{2}{|c|}{ pH } \\
\hline & & & Sorption & Desorption & Unfiltered & Filtered & Initial & Final \\
\hline YM-54 & $<75$ & $4.7 \times 10^{-12}$ & 21.6 & 89.9 & $\begin{array}{r}66 \\
830\end{array}$ & $\begin{array}{r}68 \\
820\end{array}$ & $\begin{array}{l}8.70 \\
8.55\end{array}$ & $\begin{array}{l}7.71 \\
8.44\end{array}$ \\
\hline & & & 42.6 & 67.8 & $\begin{array}{r}64 \\
590\end{array}$ & $\begin{array}{r}63 \\
640\end{array}$ & $\begin{array}{l}8.70 \\
7.85\end{array}$ & $\begin{array}{l}7.79 \\
8.43\end{array}$ \\
\hline & & & 84.6 & & $\begin{array}{r}780 \\
\end{array}$ & 76 & 8.70 & 8.48 \\
\hline & & & & 20.9 & 670 & 720 & 8.29 & 8.34 \\
\hline & $75-500$ & & 21.6 & & 52 & 54 & 8.70 & 7.73 \\
\hline & & & & 89.9 & 660 & 850 & 8.55 & 8.47 \\
\hline & & & 42.6 & & 81 & 86 & 8.70 & 7.84 \\
\hline & & & & 67.8 & 600 & 700 & 7.85 & 8.47 \\
\hline & & & 84.6 & & 160 & 210 & 8.70 & 8.52 \\
\hline & & & & 20.9 & 660 & 850 & 8.29 & 8.36 \\
\hline
\end{tabular}

All measurements were made at ambient temperature $\left(\sim 22^{\circ} \mathrm{C}\right)$.

${ }^{b}$ All feed solutions were filtered through 0.4 - and $0.05 \mu$ m Nuclepore filters. 
TABLE III

${ }^{237}$ Pu SORPTION RATIOS, CONTROLLED-ATMOSPHERE CONDITIONS ${ }^{a}$

\begin{tabular}{|c|c|c|c|c|c|c|c|c|}
\hline \multirow[b]{2}{*}{ Core } & \multirow{2}{*}{$\begin{array}{l}\text { Fraction } \\
(\mu i)\end{array}$} & \multirow{2}{*}{$\begin{array}{l}\text { Approximate } \\
\text { Pu Molarity } \\
\end{array}$} & \multicolumn{2}{|c|}{ Time (d) } & \multicolumn{2}{|c|}{$R_{d}(m \ell / g)$} & \multicolumn{2}{|c|}{$\mathrm{pH}$} \\
\hline & & & Sorption & Desorption & Unfiltered & Filtered & Initial & Final \\
\hline YM-22 & $<75$ & $4.1 \times 10^{-13}$ & 20.7 & & 85 & 84 & 9.25 & 9.01 \\
\hline & & & & 85.8 & 1000 & 1800 & 9.20 & 9.34 \\
\hline & & & 48.7 & & 260 & 250 & 9.25 & 8.87 \\
\hline & & & & 54.7 & 1500 & 2150 & 9.13 & 9.32 \\
\hline & & & 84.7 & & 190 & 280 & 9.25 & 9.22 \\
\hline & $75-500$ & & & 21.8 & 3100 & 4200 & 9.57 & 9.07 \\
\hline & $15-500$ & & 20.7 & & 120 & 130 & 9.25 & 8.88 \\
\hline & & & 107 & 86.8 & 970 & 2800 & 9.20 & 9.69 \\
\hline & & & 48.7 & & 400 & 430 & 9.25 & 8.72 \\
\hline & & & 847 & 55.7 & 1800 & 3300 & 9.13 & 9.36 \\
\hline & & & & 248 & 250 & 280 & 9.25 & 9.17 \\
\hline YM-38 & $<75$ & $1.7 \times 10^{-13}$ & 20.7 & 24.8 & 1200 & 3900 & 9.67 & 9.01 \\
\hline & & & & 85.8 & $>2200$ & $>2200$ & $\begin{array}{l}8.81 \\
8.88\end{array}$ & $\begin{array}{l}8.75 \\
9.41\end{array}$ \\
\hline & & & 47.7 & & 930 & 1200 & 8.87 & 8.67 \\
\hline & & & & 54.7 & $>2000$ & $>2 \quad 200$ & 8.80 & 8.92 \\
\hline & & & 83.7 & & 1100 & 1000 & 8.87 & 9.06 \\
\hline & & & & 21.8 & $>2600$ & $>2600$ & 9.30 & 8.98 \\
\hline & $75-500$ & & 20.7 & & 620 & 640 & 8.87 & 8.76 \\
\hline & & & & 86.8 & $>2 \quad 400$ & $>2400$ & 8.88 & 8.90 \\
\hline & & & 48.7 & & 830 & 760 & 8.87 & 8.79 \\
\hline & & & & 55.7 & $>2200$ & $>2 \quad 200$ & 8.80 & 8.93 \\
\hline & & & 83.7 & & 830 & 1000 & 8.87 & 9.17 \\
\hline & & & & 24.8 & $>2300$ & $>2300$ & 9.30 & 8.72 \\
\hline
\end{tabular}




\section{TABLE III (cont)}

${ }^{237}$ Pu SORPTION RATIOS, CONTROLLED-ATMOSPHERE CONDITIONS ${ }^{a}$

\begin{tabular}{|c|c|c|c|c|c|c|c|c|}
\hline \multirow[b]{2}{*}{ Core } & \multirow{2}{*}{$\begin{array}{l}\text { Fraction } \\
\quad(\mu \mathrm{m}) \\
\end{array}$} & \multirow{2}{*}{$\begin{array}{l}\text { Approximate } \\
\text { Pu Molarity }\end{array}$} & \multicolumn{2}{|c|}{ Time(d) } & \multicolumn{2}{|c|}{$R_{d}(m \ell / g)$} & \multicolumn{2}{|c|}{$\mathrm{pH}$} \\
\hline & & & Sorption & Desorption & Unfiltered & Filtered & Initial & Final \\
\hline YM-54 & $<75$ & $2.6 \times 10^{-13}$ & 21.7 & & 65 & 69 & 9.29 & 8.88 \\
\hline & & & & 85.8 & 1000 & 2300 & 9.09 & 9.60 \\
\hline & & & 48.7 & & 100 & 100 & 9.29 & 8.73 \\
\hline & & & & 54.7 & 780 & $>2600$ & 9.13 & 9.22 \\
\hline & & & 84.7 & & 120 & 190 & 9.29 & 9.25 \\
\hline & & & & 21.8 & 1900 & $>3500$ & 9.50 & 9.08 \\
\hline & $75-500$ & & 21.7 & & 110 & 96 & 9.29 & 8.91 \\
\hline & & & & 86.8 & 855 & 3000 & 9.09 & 9.33 \\
\hline & & & 49.7 & & 205 & 210 & 9.29 & 8.82 \\
\hline & & & & 55.7 & 1600 & $>2800$ & 9.13 & 9.20 \\
\hline & & & 84.7 & & 190 & 2.60 & 9.29 & 9.09 \\
\hline & & & & 24.8 & 1500 & 3200 & 9.50 & 9.02 \\
\hline
\end{tabular}

\footnotetext{
${ }^{a}$ Nitrogen, $\leqq 0.2 \mathrm{ppm}$ oxygen, $\$ 20 \mathrm{ppm}$ carbon dioxide. Measurements were made at $32^{\circ} \mathrm{C}$.

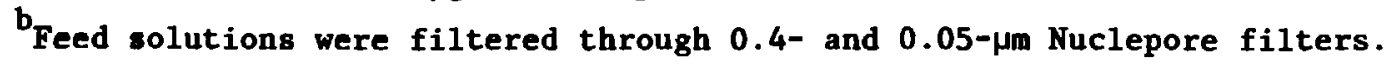


TABLE IV

${ }^{241}$ Am SORPTION RATIOS, ATMOSPHERIC CONDITIONS ${ }^{a}$

\begin{tabular}{|c|c|c|c|c|c|c|c|c|}
\hline \multirow[b]{2}{*}{ Core } & \multirow{2}{*}{$\begin{array}{c}\text { Fraction } \\
(\mu m)\end{array}$} & \multirow{2}{*}{$\begin{array}{l}\text { Approximate } \\
\text { Am Molarity }^{b}\end{array}$} & \multicolumn{2}{|c|}{ Time (d) } & \multicolumn{2}{|c|}{$R_{d}(m l / g)$} & \multicolumn{2}{|c|}{$\mathrm{pH}$} \\
\hline & & & Sorption & Desorption & Unfiltered & Filtered & Initial & Final \\
\hline YM-22 & $<75$ & $1.4 \times 10^{-7}$ & 20.8 & 82.8 & $\begin{array}{ll}6 & 500 \\
6 & 700\end{array}$ & $\begin{array}{ll}9 & 500 \\
9 & 000\end{array}$ & $\begin{array}{l}8.60 \\
7.80\end{array}$ & $\begin{array}{l}7.75 \\
8.46\end{array}$ \\
\hline & & & 43.8 & & 6800 & 10000 & 8.60 & 8.37 \\
\hline & & & & 61.7 & 6500 & 8500 & 8.37 & 8.47 \\
\hline & & & 86.8 & & 6900 & 9800 & 8.60 & 8.31 \\
\hline & & & & 19.8 & 7300 & 11000 & 8.28 & 8.52 \\
\hline & $75-500$ & & 20.8 & & 1500 & 1900 & 8.60 & 7.76 \\
\hline & & & & 82.8 & 2400 & 3100 & 7.80 & 8.48 \\
\hline & & & 43.8 & & 1100 & 1600 & 8.60 & 8.40 \\
\hline & & & & 61.7 & 1900 & $270 \mathrm{C}$ & 8.37 & 8.48 \\
\hline & & & 86.8 & & 1100 & 1700 & 8.60 & 8.32 \\
\hline & & & & 19.8 & 3100 & 4500 & 8.28 & 8.51 \\
\hline YM-38 & $<75$ & $1.4 \times 10^{-1}$ & 21.8 & & 9500 & 21000 & 8.59 & 7.63 \\
\hline & & & & 86.9 & 9900 & 23000 & -- & 8.38 \\
\hline & & & 42.8 & & 7300 & 18000 & 8.59 & 8.44 \\
\hline & & & & 63.7 & 13500 & 22000 & 8.44 & 8.23 \\
\hline & & & 83.8 & & 2600 & 6800 & 8.59 & 8.31 \\
\hline & & & & 28.7 & 12000 & 25000 & 8.26 & 8.45 \\
\hline & $75-500$ & & 21.8 & & 6100 & 15000 & 8.59 & 7.68 \\
\hline & & & & 86.9 & 5900 & 13000 & -- & 8.35 \\
\hline & & & 42.8 & & 5200 & 14000 & 8.59 & 8.46 \\
\hline & & & & 63.7 & 9600 & 19000 & 8.44 & 8.28 \\
\hline & & & 83.8 & & 2500 & 8000 & 8.59 & 8.33 \\
\hline & & & & 28.7 & 5800 & 13000 & 8.26 & 8.42 \\
\hline
\end{tabular}


TABLE IV (cont)

${ }^{241}$ Am SORPTION RATIOS, ATMOSPHERIC CONDITIONS ${ }^{a}$

\begin{tabular}{|c|c|c|c|c|c|c|c|c|}
\hline \multirow[b]{2}{*}{ Core } & \multirow{2}{*}{$\begin{array}{l}\text { Fraction } \\
(\boldsymbol{( \mu )}) \\
\end{array}$} & \multirow{2}{*}{$\begin{array}{l}\text { Approximate } \\
\text { An Molarity }\end{array}$} & \multicolumn{2}{|c|}{ Time (d) } & \multicolumn{2}{|c|}{$R_{d}(m \ell / g)$} & \multicolumn{2}{|c|}{ pH } \\
\hline & & & Sorption & Desorption & Unfiltered & Filtered & Initial & Fina1 \\
\hline \multirow[t]{11}{*}{ YM-54 } & $<75$ & $1.5 \times 10^{-7}$ & 20.8 & & 900 & 1200 & 8.63 & 7.76 \\
\hline & & & & 82.8 & 690 & 1000 & 7.82 & 8.52 \\
\hline & & & 45.8 & & 1300 & 2400 & & 8.43 \\
\hline & & & 86.8 & 01.1 & 900 & 1600 & 8.63 & 8.33 \\
\hline & & & & 19.8 & 560 & 940 & 8.43 & 8.58 \\
\hline & $75-500$ & & 20.8 & & 150 & 180 & 8.63 & 7.79 \\
\hline & & & & 82.8 & 400 & 520 & 7.82 & 8.54 \\
\hline & & & 43.8 & & 150 & 240 & 8.63 & 8.51 \\
\hline & & & & 61.7 & 680 & 1100 & 8.52 & 8.55 \\
\hline & & & 86.8 & & 160 & 240 & 8.63 & 8.41 \\
\hline & & & & 19.8 & 570 & 840 & 8.43 & 8.58 \\
\hline
\end{tabular}

All measurements were made at ambient temperature $\left(\sim 22^{\circ} \mathrm{C}\right)$.

${ }^{b}$ All feed solutions were filtered through $0.4-$ and $0.05-\mu m$ Nuclepore filters. 
TABLE V

${ }^{241}$ Am SORPTION RATIOS, CONTROLLED-ATMOSPHERE CONDITIONS ${ }^{a}$

\begin{tabular}{|c|c|c|c|c|c|c|c|c|}
\hline \multirow[b]{2}{*}{ Core } & \multirow{2}{*}{$\begin{array}{l}\text { Fraction } \\
(\mu \mathrm{m}) \\
\end{array}$} & \multirow{2}{*}{$\begin{array}{l}\text { Approximate } \\
\text { Am Molarity }\end{array}$} & \multicolumn{2}{|c|}{ Time(d) } & \multicolumn{2}{|c|}{$R_{d}(m \ell / g)$} & \multicolumn{2}{|c|}{$\mathrm{pH}$} \\
\hline & & & Sorption & Desorption & Unfiltered & Filtered & Initial & Final \\
\hline \multirow[t]{12}{*}{ YM-22 } & $<75$ & $3.1 \times 10^{-8}$ & 20.7 & & 1400 & 2200 & 9.12 & 9.15 \\
\hline & & & & 83.8 & 2500 & 7900 & 9.15 & 8.76 \\
\hline & & & 41.7 & & 2100 & 2800 & 9.12 & 9.08 \\
\hline & & & & 63.9 & 3100 & 7500 & 9.04 & 8.80 \\
\hline & & & 89.7 & & 1800 & 3600 & 9.12 & 8.92 \\
\hline & & & & 18.8 & 7500 & 12000 & 9.27 & 9.00 \\
\hline & $75-500$ & & 20.7 & & 750 & 1000 & 9.12 & 9.16 \\
\hline & & & & 83.8 & 2300 & 3800 & 9.15 & 8.80 \\
\hline & & & 41.7 & & 960 & 1200 & 9.12 & 9.05 \\
\hline & & & & 63.9 & 2300 & 4900 & 9.04 & 8.86 \\
\hline & & & 89.7 & & 1200 & 1800 & 9.12 & 8.94 \\
\hline & & & & 18.8 & 4300 & 9200 & 9.27 & 9.03 \\
\hline \multirow[t]{12}{*}{ YM-38 } & $<75$ & $3.4 \times 10^{-8}$ & 20.7 & & 4600 & 12000 & 9.45 & 8.78 \\
\hline & & & & 84.7 & 18000 & 61000 & -- & 8.24 \\
\hline & & & 43.7 & & 8800 & 28000 & 9.45 & 9.24 \\
\hline & & & & 63.9 & 10000 & 54000 & 9.19 & 8.40 \\
\hline & & & 83.7 & & 8200 & 39000 & 9.45 & 8.54 \\
\hline & & & & 22.8 & 19000 & 41000 & 8.56 & 8.53 \\
\hline & $75-500$ & & 20.7 & & 3400 & 14000 & 9.45 & 8.77 \\
\hline & & & & 84.7 & 18000 & 24000 & -- & 8.39 \\
\hline & & & 43.7 & & 3600 & 31000 & 9.45 & 9.21 \\
\hline & & & & 63.9 & 8400 & 64000 & 9.19 & 8.44 \\
\hline & & & 83.7 & & 5000 & 33000 & 9.45 & 8.57 \\
\hline & & & & 22.8 & 9100 & 11000 & 8.56 & 8.60 \\
\hline
\end{tabular}




\section{TABLE V (cont)}

${ }^{241}$ Am SORPTION RATIOS, CONTROLLED-ATMOSPHERE CONDITIONS ${ }^{a}$

\begin{tabular}{|c|c|c|c|c|c|c|c|c|}
\hline \multirow[b]{2}{*}{ Core } & \multirow{2}{*}{$\begin{array}{c}\text { Fraction } \\
(\mu \mathrm{m}) \\
\end{array}$} & \multirow{2}{*}{$\begin{array}{l}\text { Approximate } \\
\text { Am Molarity }\end{array}$} & \multicolumn{2}{|c|}{ Time (d) } & \multicolumn{2}{|c|}{$R_{d}(m \ell / g)$} & \multicolumn{2}{|c|}{ pH } \\
\hline & & & Sorption & Desorption & Unfiltered & Filtered & Initial & Final \\
\hline \multirow[t]{12}{*}{ YM-54 } & $<75$ & $1.1 \times 10^{-7}$ & 19.8 & & 1000 & 3600 & 9.03 & 9.12 \\
\hline & & & & 83.8 & 2. 400 & 12000 & 9.14 & 8.80 \\
\hline & & & 41.8 & & 1400 & 4900 & 9.03 & 9.14 \\
\hline & & & & 62.7 & 3200 & 18000 & 9.09 & 8.99 \\
\hline & & & 88.8 & & 1900 & 6500 & 9.03 & 8.87 \\
\hline & & & & 18.8 & 3800 & 21000 & 8.65 & 8.97 \\
\hline & $75-500$ & & 19.8 & & 650 & 2400 & 9.03 & 9.13 \\
\hline & & & & 83.8 & 1400 & 5700 & 9.14 & 8.76 \\
\hline & & & 41.8 & & 620 & 3000 & 9.03 & 9.04 \\
\hline & & & & 62.7 & 1600 & $10 \quad 000$ & 9.09 & 8.89 \\
\hline & & & 88.8 & & 660 & 4000 & 9.03 & 8.87 \\
\hline & & & & 18.8 & 2900 & 16000 & 8.65 & 9.07 \\
\hline
\end{tabular}

\footnotetext{
${ }^{a}$ Nitrogen, $\leqq 0.2 \mathrm{ppm}$ oxygen, $\leqq 20 \mathrm{ppm}$ carbon dioxide. All measurements were made at $32^{\circ} \mathrm{C}$.
}

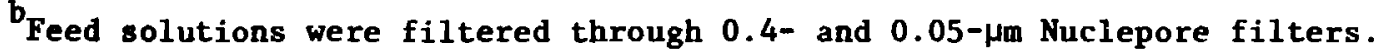


TABLE VI

AVERAGE $^{\mathrm{a}}$ SORPTION RATIOS $(\mathrm{m} / \mathrm{g})$ FOR Am AND Pu UNDER ATMOSPHERIC AND CONTROLLED-ATMOSPHERE ${ }^{b}$ CONDITIONS

\begin{tabular}{|c|c|c|c|c|c|}
\hline \multirow[b]{2}{*}{ Tracer } & \multirow[b]{2}{*}{ Core } & \multicolumn{2}{|c|}{ Sorption } & \multicolumn{2}{|c|}{ Desorption } \\
\hline & & Atmospheric & Controlled & Atmospheric & Controlled \\
\hline \multirow[t]{3}{*}{${ }^{237} \mathrm{Pu}$} & YM-22 & $140(38)^{c}$ & $220(46)$ & $1400(95)$ & $1600(330)$ \\
\hline & $Y M-38$ & $250(88)$ & $800(87)$ & $2000(490)$ & $>2200$ \\
\hline & $Y M-54$ & $84(17)$ & $120(29)$ & $670(35)$ & $1300(190)$ \\
\hline \multirow[t]{3}{*}{$241_{\mathrm{Am}}$} & $Y M-22$ & $4000\left(\begin{array}{ll}1 & 200\end{array}\right)$ & $1400(210)$ & $4600(990)$ & $3700(830)$ \\
\hline & $Y M-38$ & $5500\left(\begin{array}{ll}1 & 100\end{array}\right)$ & $5600(950)$ & $9500\left(\begin{array}{ll}1 & 300\end{array}\right)$ & $14000\left(\begin{array}{ll}2 & 100\end{array}\right)$ \\
\hline & $Y M-54$ & $590(200)$ & $1000(210)$ & $600(45)$ & $2500(380)$ \\
\hline \multicolumn{6}{|c|}{ 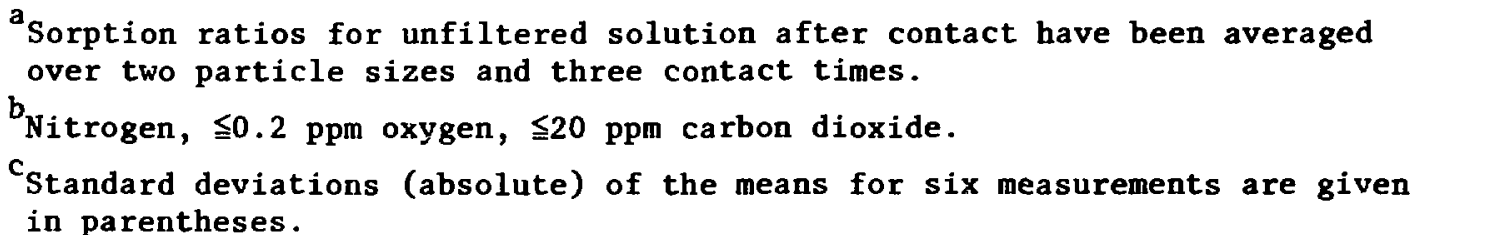 } \\
\hline
\end{tabular}

desorption under controlled-atmosphere conditions. For the YM-54 (devitrified) sample and the $Y M-38$ (zeolitized) sample, americium $R_{d}$ values for both soxption and desorption are either the same or slightly greater under the controlled atmosphere. As reported ${ }^{2}$ previously, americium has also exhibited a tendency toward large variations in behavior when experimental conditions are changed. This, also, is probably due to speciation effects.

As observed ${ }^{2}$ before, sorption ratios for americium and plutonium on zeolitized tuffs such as YM-38 tend to be higher than those for devitrified tuffs such as YM-22 and YM-54. Current results, however, indicate significant differences between the two devitrified tuffs.

Within the errors on the data, particle-size effects appear to be minimal as, for the most part, do changes with contact tine. Variations $I n R_{d}$ values with particle size that do occur appear to be in different directions for different conditions. Where any contact-time effects can be observed, the trend, as expected, is an increase in $R_{d}$ values with increasing time. Again, as usual, desorption $R_{d}$ values tend to be higher than those for sorption; possible reasons for this effect have been discussed in earlier reports. 1,2 
IV. URANIUM(VI) SORPTION STULIES

Uranium may be an important component in nuclear waste. Because strong reducing conditions are necessary to reduce $U(V I)$ to $U($ IV) and because U(VI) forms anionic complexes that sorb poorly on rocks, it is necessary to know the migration behavior of the element.

Uranium(VI) sorption ratios measured under atmospheric conditions are listed in Table VII for Yucca Mountain cores. The average values are given in Table VIII. The sorption and desorption values for sample YM-38 (zeolitized) are a factor of 3 to 4 less in air than under controlled-atmosphere conditions $^{2}$ ( $\leqq 0.2 \mathrm{ppm}$ oxygen and $\leqq 20 \mathrm{ppm}$ carbon dioxide). However, sample YM-22 (devitrified) appears to sorb uranium better in air than in the controlled atmosphere, ${ }^{2}$ even considering the large uncertainties associated with the small sorption ratios. Approximate values in the controlled atmosphere are $0.5,15$, and $1.5 \mathrm{ml} / \mathrm{g}$ for samples YM-22, YM-38, and YM-54, respectively.

V. COMPARISON OF BATCH STUDIES MADE UNDER ATMOSPHERIC AND CONTROLLEDATMOSPHERE CONDITIONS

Because reducing conditions are expected for some groundwater-rock systems, it may be anticipated that the sorptive behavior of some elements will be different in such systems from that under normal atmospheric conditions. One could also expect differences in the sorptive capacity of a rock if its surface were altered by exposure to air. These effects were investigated by comparing the results of studies performed in a nitrogen atmosphere ( $\$ 0.2$ ppm oxygen and $\leqq 20 \mathrm{ppm}$ carbon dioxide) with similar measurements made under normal atmospheric conditions on the same geologic materials. It should be emphasized that the controlled-atmosphere studies are not truly representative of the conditions to be found in deep geologic systems because essentially no carbon dioxide was present.

The $\mathrm{pH}$ values of the groundwaters after the experiments in the controlled atmosphere were 0.5 unit higher than for similar experiments in air (see, for example, Tables IV and $V$ ). This may be a consequence of some loss of carbon dioxide (and total carbonate) from solution and may affect sorption of uranium(VI), which is strongly conplexed by carbonate. The increase in pH may decrease the solubility of some multivalent ions significantly and may also result in changes in ionic charge, degree of hydration, etc. 
TABLE VII

U(VI) SORPTION RATIOS, ATMOSPHERIC CONDITIONS ${ }^{a}$

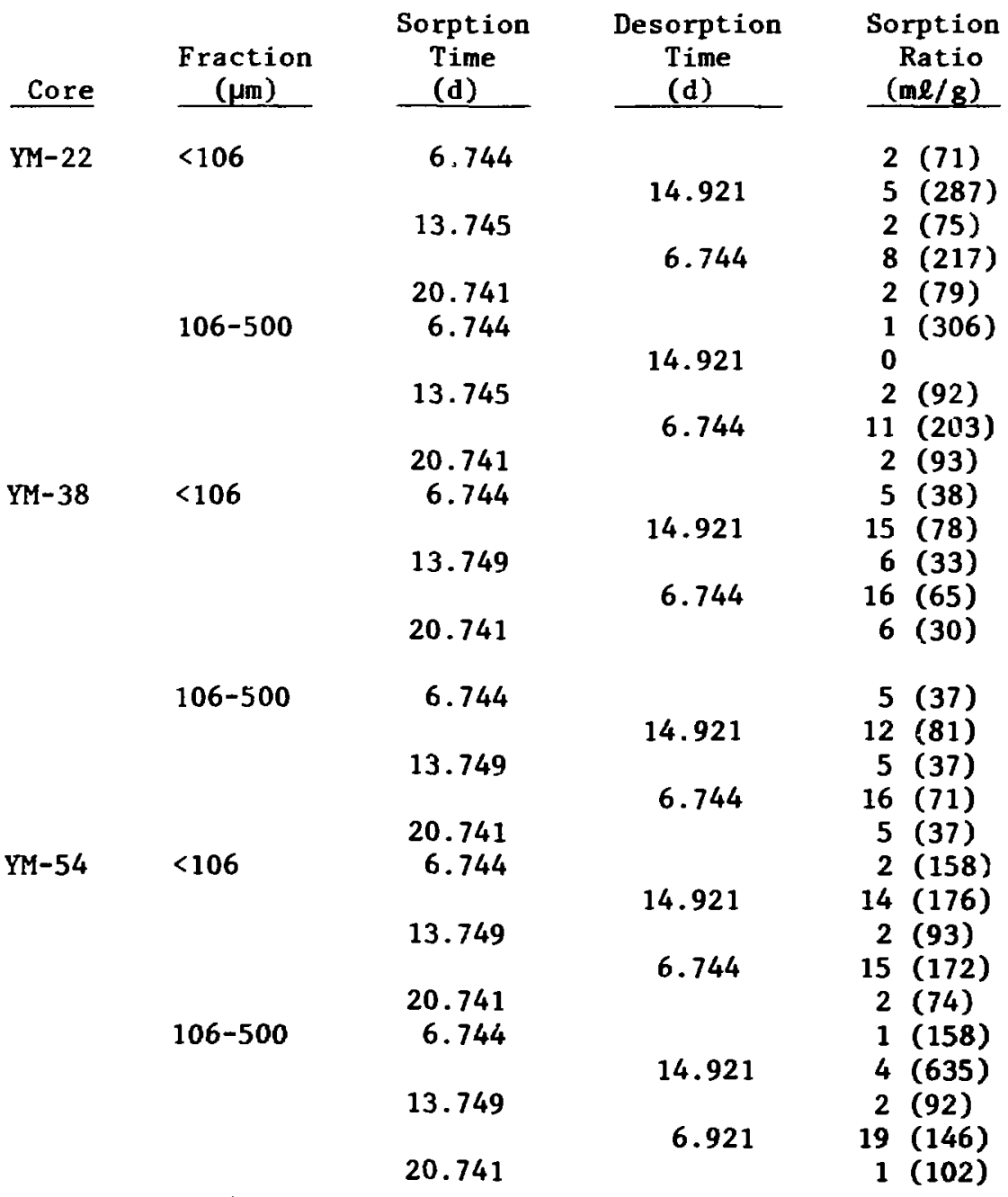

${ }^{a_{T}}$ The values in parentheses axe the standard deviations for a single measurement of the $R_{\text {d }}$ value expressed in percent; these were obtained from the srrors associated with the activity measurements and estimated uncertainties for the various parameters entering into the calculation; these estimated uncertainties were propagated using the rule for change of variables in a moment matrix assuming independence of the variables. 
TABIE VIII

AVERAGE U(VI) SORPTION RATIOS, ATMOSPHERIC CONDITIONS

\begin{tabular}{|c|c|c|c|}
\hline \multirow[b]{2}{*}{ Core } & \multirow{2}{*}{$\begin{array}{c}\text { Fraction } \\
(\mu \mathrm{m}) \\
\end{array}$} & \multicolumn{2}{|c|}{$R_{d}(m \ell / g)$} \\
\hline & & Sorption & Desorption \\
\hline \multirow[t]{2}{*}{ YM-22 } & $<106$ & 2.0 & 6.4 \\
\hline & $106-500$ & 1.2 & 5.6 \\
\hline \multirow[t]{2}{*}{$Y M-38$} & $<106$ & 5.5 & 15.1 \\
\hline & $106=500$ & 4.7 & 14,1 \\
\hline \multirow[t]{2}{*}{ YM-54 } & $<106$ & 1.9 & 14.3 \\
\hline & $106-500$ & 1.4 & 11.3 \\
\hline
\end{tabular}

The experimental techniques and calculational methods have been reported earlier. ${ }^{1,2}$ The radionuclides were ${ }^{85} \mathrm{sr},{ }^{137} \mathrm{Cs},{ }^{133} \mathrm{Ba},{ }^{141} \mathrm{Ce},{ }^{152} \mathrm{Eu},{ }^{95 \mathrm{~m}} \mathrm{Tc}$, ${ }^{237} \mathrm{U},{ }^{237} \mathrm{Pu}$, and ${ }^{241} \mathrm{Aln}$. The rock samples were from Yucca Mountain tuff cores YM-22, YM-38, and YM-54. The groundwaters used in the determinations in air and nitrogen atmospheres had the same initial composition. Fractions of $<75 \mu \mathrm{m}$ and 75 to $500 \mu \mathrm{m}$ were used for most studies under both conditions; fractions of $<106 \mu \mathrm{m}$ and 106 to $500 \mu \mathrm{m}$ were used in some experiments under atmospheric conditions.

A. Results and Observations

The $R_{d}$ values from both sorption and desorption studies were reported earlier. Atmospheric $R_{d}$ values for tuff were reported in Refs. 1 and 2 and Sec. IV above. Results obtained under controlled-atmosphere conditions were reported in Ref. 2 and Sec. III above. General comparisc.ns of the sorptive behavior of tuff for various element: follow.

1. Cesium. The cesium $R_{d}$ values for the three tuff samples studied in the controlled-atmosphere experiments are higher for the smaller particle size than for the larger one; however, this dependence on particle size is less than that observed in the measurenents carried out under atmospheric conditions. The sorptive behavior of cesjum on tuff appears to be independent of the atmosphere involved.

2. Strontiun. A smill dependence on particle size is observed for the sorption of strontium on Yuccs Mountain tuffs under controlled-atmosphere 
conditions. There does not seem to be a time dependence for sorption ratios in either atmosphere. The strontium $R_{d}$ values are essentially the same for atmospheric and controlled-atmosphere conditions.

3. Barium. The controlled-atmosphere deterwinations show a particle-size effect for barium sorption on the three tuff samples. The dependence was not observed in the atmospheric measurements. Changing the atmosphere did not seem to have any major effect on the sorptive behavior.

4. Cerium and Europium. The $R_{d}$ values are similar for the two different atmospheres. The sorption of cerium and europium may be strongly dependent on the formation of insoluble forms of these elements (namely, precipitates or colloids).

5. Technetiun. Technetiun sorbs more strongly in the controlled atmospinere. The sorption ratios on zeolitic tuffs are about 15 times larger under controlled-atmosphere conditions than in air. The values for devitrified tuffs are 10 to 25 times larger under the controlled-atmosphere conditions.

6. Uranium. Under controlled-atmosphere conditions, the sorption ratios are similar to those in air for MM-22 and YM-54 samples (devitrified) but somewhat higher for MM-38 tuff (zeolitized). It was anticipated that uranium(VI) might be reduced to uranium(IV) under the controlled-atmosphere conditions and that more sorption might take place; apparently this did not happen. The uranium(VI) may remain strongly complexed by carbonate in the groundwater.

7. Plutonium. The $R_{d}$ values for both the sorption and desorption of plutonium for all three tuffs are significantly higher under controlledatmosphere conditions than in air. Such a change with a change in atmosphere is not surprising considering the known tendency of plutonium to exhibit large variations in behavior when experimental conditions are changed, presumably due to speciation effects.

8. Americiun. For the YM-22 (devitrified) tuff, anericiun has lower $R_{d}$ values for both sorption and desorption under the controlled atmosphere. For the sample YM-54 (devitrified) and sample YM-38 (zeolitized), anericium $\mathbf{R}_{\mathbf{d}}$ values for both sorption and desorption are either the sane or slightly greater und $c r$ che controlled atwosphere. As reported ${ }^{2}$ previously, americium has also exhibited a tendency toward large variations in behavior when experimental conditions are changed, which may also be due to speciation effects. 


\section{B. General Conclusions}

The effects of atmosphere on the sorption ratios of the nine elements studied are sumarized in Table IX. The $R_{d}$ values for strontiun, cesium, barium, cerium, and europium on tuff samples are not affected significantly by the presence or absence of oxygen and carbon dioxide. The $R_{d}$ values for technetium and plutonium are most strongly dependent on atmosphere; they are higher when measured under controlled-atmosphere conditions. The $R_{d}$ values for uraniun are higher for zeolitized tuff only under controlled-atmosphere conditions.

VI. DEPENDENCE OF SORPTION ON THE SOLUTION-TO-SOLID RATIO

Although batch sorption measurements allow for the investigation of many variables that would be difficult to investigate in column experiments, it is necessary to conduct the batch experiments under unrealistic proportions of rock and water. The solution-to-solid ratio even in a porous rock is

TABLE IX

COMPARISON OF SORPTION RATIOS ( $R_{d}$ ) MEASURED UNDER ATMOSPHERIC AND CONTROLLED-ATMOSPHERE (CA) CONDITIONS ${ }^{a}$

\begin{tabular}{cc} 
Elenent & Effect \\
\cline { 2 - 2 } Cs & No effect \\
$\mathrm{Sr}$ & No effect \\
$\mathrm{Ba}$ & No effect \\
$\mathrm{Ce}$ & No effect \\
$\mathrm{Eu}$ & No effect \\
$\mathrm{TC}$ & Higher in $\mathrm{CA}$ \\
$\mathrm{U}$ & (factor of $\geq 10$ ) \\
& Higher in CA \\
$\mathrm{Pu}$ & (factor of $2-3$ ) \\
& Higher in $\mathrm{CA}$ \\
$\mathrm{Am}$ & (factor of 2 ) \\
& No effect
\end{tabular}

\footnotetext{
Mitrogen, 50.2 ppa oxygen and $\$ 20$ ppe carbon dioxide.

${ }^{b}$ m-38 (zeolitized) tuff only; otherwise no effect.

CMay depend on mineralogy.
} 
$<1: 1$, whereas the ratio in our batch experiments has been 20:1. An investigation of the effect of changing this ratio is being performed.

The MM-22 (devitrified) and YM-38 (zeolitic) samples were selected for these experiments, and two fraction sizes, $<75 \mu \mathrm{m}$ and 75 to $500 \mu \mathrm{m}$, were used. The procedures for preparing feed solutions and for performing batch determinations have been given before. ${ }^{1,2}$ The radionuclides used for these studies were ${ }^{85} \mathrm{Sr},{ }^{137} \mathrm{Cs},{ }^{133} \mathrm{Ba},{ }^{141} \mathrm{Ce}$, and ${ }^{152} \mathrm{Eu}$. The experiments were performed with three solution-to-solid ratios, 5:1, 10:1, and $30: 1$. Contact times were 3 and 6 weeks at ambient temperature under atmospheric conditions. Results are presented in Tables $X$ and XI; for the YM-22 samples only, the 3-week results were available for this report.

The sorption ratios for tuff YM-38 increase as the solution-to-solid ratio is increased from $5: 1$ to $30: 1$. For cesium and strontiun, the increase is small; whereas for barium, cerium, and europium, there are large increases (a factor of $\sim 8$ in most cases). For YM-22 samples the effect is less noticeable than for YM-38 samples. Cesium, strontium, and barium sorption ratios remain rather constant at different solution-to-solid ratios. Ceriun and europiu sorption ratios increase with an increase in the solution-to-solid ratio. This may be a manifestation of a different sorption mechanism for lanthanides than for strontium, cesium, and barium, which probably sorb by ion exchange processes. Again, tuff YM-38 shows a larger effect than tuff YM-22.

The solution-to-solid ratios under natural conditions and in colum experiments are much smaller than those of the laboratory batch experiments. The observation of generally decreasing sorption ratios with decreasing solution-to-solid ratios may be at least a partial explanation for the lower sorption ratios ${ }^{5,6}$ deduced from the crushed-tuff column experiments.

\section{DEPENDENCE OF SORPTION ON ELEMENT CONCENTRATION -- ISOTHERYS}

Most of our experiments have been conducted with only trace concentrations, usually $<10^{-6} \mathrm{M}$, of the sorbing element. Higher concentrations may be a possibility in sone repository release scenarios, particularly in the near-field environment. Batch sorption experiments are being performed to determine the dependence of the sorption ratio on the concentration of the element studied. These data also give indications of wechanisas (ion exchange or precipitation) for removal of the element from solution. Experinents with strontium, cesium, 
TABLE $X$

VARIATION OF SORPTION RATIO WITH SOLUTION-TO-SOLID RATIO - SAMPLE YM-22 ${ }^{a, b}$

\begin{tabular}{|c|c|c|c|c|c|c|}
\hline \multirow{2}{*}{$\begin{array}{l}\text { Fraction } \\
\text { (ر) } \\
\end{array}$} & \multirow{2}{*}{$\begin{array}{c}\text { Solution:Solid } \\
\text { Ratio } \\
\end{array}$} & \multicolumn{5}{|c|}{$R_{d}(m l / g)$} \\
\hline & & $\mathrm{Cs}$ & $\mathbf{S r}$ & $\mathbf{B a}$ & $\mathrm{Ce}$ & $\mathbf{E u}$ \\
\hline \multirow[t]{3}{*}{$<75$} & $5: 1$ & $827(4.7)$ & $122(2.0)$ & $1490(1.8)$ & $459(8.5)$ & $926(7.8)$ \\
\hline & $10: 1$ & $755(2.9)$ & $80.3(2.1)$ & $1360(1.4)$ & $500(5.7)$ & $1270(5.2)$ \\
\hline & $30: 1$ & $749(2.1)$ & $67.4(2.5)$ & $1010(1.1)$ & $1050(4.5)$ & $1640(3.5)$ \\
\hline \multirow[t]{3}{*}{$75-500$} & $5: 1$ & $363(3.4)$ & $63.0(2.0)$ & $601(2.2)$ & $303(6.6)$ & $794(6.7)$ \\
\hline & $10: 1$ & $336(2.5)$ & $44.9(2.2)$ & $530(1.9)$ & $508(5.4)$ & $909(4.8)$ \\
\hline & $30: 1$ & $368(2.2)$ & $195(2.0)$ & $412(1.9)$ & $1000(4.6)$ & $1600(3.5)$ \\
\hline
\end{tabular}

\footnotetext{
acontact time of 3 weeks.
}

${ }^{b}$ See footnote a, Table VII. 
TABLE XI

VARIATION OF SORPTION RATIO WITH SOLUTION-TO-SOLID RATIO - SAMPLE YM-38 ${ }^{a}$

\begin{tabular}{|c|c|c|c|c|c|c|c|}
\hline \multirow{2}{*}{$\begin{array}{l}\text { Fraction } \\
(\mu) \\
\end{array}$} & \multirow{2}{*}{$\begin{array}{c}\text { Solution:Solid } \\
\text { Ratio } \\
\end{array}$} & \multicolumn{6}{|c|}{$R_{d}(m l / g)$} \\
\hline & & $\mathrm{Cs}$ & $\mathrm{Sr}$ & $\mathrm{Ba}$ & $\mathrm{Ce}$ & & Eu \\
\hline \multirow[t]{6}{*}{$<75$} & $5: 1^{b}$ & $5970(11.7)$ & $2770(5.4)$ & $11000(5.1)$ & $1330(17.3)$ & 2 & $700(17.7)$ \\
\hline & $10: 1^{b}$ & $5760(7.5)$ & $2790(3.4)$ & $60000(9.6)$ & $6390(13.1)$ & 9 & $070(13.2)$ \\
\hline & $30: 1^{b}$ & $7980(3.4)$ & $3610(2.2)$ & $81500(3.6)$ & $9070(6.0)$ & 9 & $700(5.4)$ \\
\hline & $5: 1^{C}$ & $5100(12.2)$ & $2370(6.4)$ & $9020(5.2)$ & $1140(20.4)$ & 2 & $160(18.4)$ \\
\hline & $10: 1^{c}$ & $5120(6.1)$ & $2410(3.4)$ & $16000(3.4)$ & $5460(15.3)$ & 4 & $330(9.4)$ \\
\hline & $30: 1^{c}$ & $8050(5.5)$ & $3700(2.4)$ & $78900(3.7)$ & $9190(8.3)$ & 6 & $000(5.7)$ \\
\hline \multirow[t]{6}{*}{$75-500$} & $5: 1^{b}$ & $3660(10.6)$ & $2040(4.9)$ & $7410(5.1)$ & $2560(17.2)$ & 3 & $060(16.3)$ \\
\hline & $10: 1^{b}$ & $5750(7.0)$ & $2840(3.3)$ & 48. $000(7.2)$ & $7230(13.0)$ & 6 & $780(11.3)$ \\
\hline & $30: 1^{b}$ & $5540(3.2)$ & $2770(2.1)$ & $54200(3.1)$ & $16000(5.8)$ & 10 & $400(4.9)$ \\
\hline & $5: 1^{c}$ & $5110(18.1)$ & $1760(5.5)$ & $6180(4.1)$ & $1600(19.3)$ & 2 & $500(17.7)$ \\
\hline & $10: 1^{C}$ & $7280(7.0)$ & $3080(3.8)$ & $23200(3.9)$ & $6050(15.3)$ & 6 & $330(11.2)$ \\
\hline & $30: 1^{c}$ & $6270(4.3)$ & $3050(2.6)$ & $49200(3.8)$ & $11600(11.3)$ & 8 & $810(7.4)$ \\
\hline
\end{tabular}

\footnotetext{
See footnote a, Table VII.

bontact time of 3 weeks.

Contact time of 6 weeks.
} 
barium, and europium have been completed; those with cerium will be reported in a subsequent report.

\section{A. Experimental}

Experiments were performed with <75- to 150- $\mu \mathrm{m}$ fractions of crushed tuff from cores $Y M-22$ and YM-38. After being pretreated with each tuff, groundwater from Well J-13 was used for preparation of the tagged solutions. Each solid sample was pretreated with water from the same well for at least 2 weeks before adding the traced solutions. All contacts for the sorption experiments were conducted for 3 weeks at ambient temperature under normal atmospheric conditions. Separate experiments were performed with each tracer.

Carrier stock solutions of strontium and barium were prepared by dissolving the nitrate salts in rock-pretreated groundwater; for cesium the chloride salt was used. Concentrations were calculated from the weights of the salts. The europium solution was prepared by dissolving $\mathrm{Eu}\left(\mathrm{NO}_{3}\right)_{3} \cdot \mathrm{xH}_{2} \mathrm{O}$ in deionized water. The europium concentration was determined to be $8.92 \times$ $10^{-3} \mathrm{M}$ with an emission spectrometer (Spectrometrics, Inc., 20-channe1, direct current, plasma source). Subsequent dilutions of the europium carrier solution were mace with the appropriate rock-pretreated groundwater.

Tracer stock solutions of ${ }^{85} \mathrm{Sr},{ }^{137} \mathrm{Cs},{ }^{133} \mathrm{Ba}$, and ${ }^{152} \mathrm{Eu}$ in the groundwaters were prepared, and solutions of different element concentrations were prepared by dilution and/or mixing of the tracer and carrier solutions. The actual concentrations of strontium and barium were determined later with the enission spectrometer. Concentration data (concentration added with carrier solutions and actual concentrations determined by emission spectrometry) and $\mathrm{pH}$ values of the solutions before contact with the rocks are given in Table XII. Element concentrations, in the solutions and on the solids after the experiments, were not measured but are based on the specific activities of the solutions in Table XII and the activities measured after the experiments. It is assumed that the solids do not contribute significant quantities of these elements. Control experiments with the europium solutions but no rock were performed to give information on europium losses from solution in the absence of the rock.

\section{B. Results and Conclusions}

The results are given in Tables XIII and XIV, and sorption ratios are plotted as a function of initial concentration in solution (Figs. 1 and 2). 
TABLE XII

INITIAL CONCENTRATIONS AND $\mathrm{pH}$ VALUES OF SOLUTIONS FOR THE ISOTHERM MEASUREMENTS

\begin{tabular}{|c|c|c|c|c|c|c|c|}
\hline \multirow[b]{3}{*}{ Element } & \multirow[b]{3}{*}{ Solution } & \multicolumn{2}{|c|}{$\mathrm{YM}-38$} & \multirow[b]{3}{*}{$\mathrm{pH}$} & \multicolumn{2}{|c|}{ YM-22 } & \multirow[b]{3}{*}{$\mathrm{pH}$} \\
\hline & & \multicolumn{2}{|c|}{ Element Concentration (M) } & & Element Con & tration $(M)$ & \\
\hline & & Added & Total & & Added & Total & \\
\hline \multirow[t]{5}{*}{$\operatorname{Sr}(I I)$} & 1 & $2.17 \times 10^{-3}$ & $2.17 \times 10^{-3}$ & 8.13 & $2.97 \times 10^{-3}$ & $2.97 \times 10^{-3}$ & 8.17 \\
\hline & 2 & $2.20 \times 10^{-5}$ & $2.20 \times 10^{-5}$ & 8.30 & $3.00 \times 10^{-5}$ & $3.11 \times 10^{-5}$ & 8.19 \\
\hline & 3 & $1.85 \times 10^{-7}$ & $2.38 \times 10^{-7}$ & 8.19 & $1.78 \times 10^{-7}$ & $1.32 \times 10^{-6}$ & 8.27 \\
\hline & 4 & $1.94 \times 10^{-8}$ & $7.28 \times 10^{-8}$ & 8.26 & $1.78 \times 10^{-8}$ & $1.16 \times 10^{-6}$ & 8.28 \\
\hline & 5 & $2.29 \times 10^{-9}$ & $5.57 \times 10^{-8}$ & 8.32 & $1.78 \times 10^{-9}$ & $1.14 \times 10^{-6}$ & 8.35 \\
\hline \multirow[t]{5}{*}{ Cs (I) } & 1 & $2.85 \times 10^{-3}$ & $2.85 \times 10^{-3}$ & 8.17 & $1.94 \times 10^{-3}$ & $1.94 \times 10^{-3}$ & 8.15 \\
\hline & 2 & $2.84 \times 10^{-5}$ & $2.84 \times 10^{-5}$ & 8.18 & $1.94 \times 10^{-5}$ & $1.94 \times 10^{-5}$ & 8.17 \\
\hline & 3 & $2.88 \times 10^{-7}$ & $2.88 \times 10^{-7}$ & 8.21 & $1.99 \times 10^{-7}$ & $1.99 \times 10^{-7}$ & 8.20 \\
\hline & 4 & $1.83 \times 10^{-9}$ & $1.83 \times 10^{-9}$ & 8.14 & $2.57 \times 10^{-9}$ & $2.57 \times 10^{-9}$ & 8.12 \\
\hline & 5 & $1.83 \times 10^{-10}$ & $1.83 \times 10^{-10}$ & 8.16 & $2.57 \times 10^{-10}$ & $2.57 \times 10^{-10}$ & 8.14 \\
\hline \multirow[t]{5}{*}{$\mathrm{Ba}(\mathrm{II})$} & 1 & $1.10 \times 10^{-4}$ & $1.10 \times 10^{-4}$ & 7.57 & $1.08 \times 10^{-4}$ & $1.07 \times 10^{-4}$ & 7.74 \\
\hline & 2 & $1.12 \times 10^{-5}$ & $1.15 \times 10^{-5}$ & 8.00 & $1.08 \times 10^{-5}$ & $1.07 \times 10^{-5}$ & 7.96 \\
\hline & 3 & $1.25 \times 10^{-6}$ & $1.62 \times 10^{-6}$ & 8.06 & $1.25 \times 10^{-7}$ & $4.17 \times 10^{-7}$ & 8.02 \\
\hline & 4 & $2.56 \times 10^{-7}$ & $6.26 \times 10^{-7}$ & 8.14 & $1.26 \times 10^{-8}$ & $3.20 \times 10^{-7}$ & 8.11 \\
\hline & 5 & $2.56 \times 10^{-8}$ & $3.95 \times 10^{-7}$ & 8.14 & $1.88 \times 10^{-8}$ & $2.95 \times 10^{-7}$ & 8.15 \\
\hline \multirow[t]{5}{*}{$\operatorname{Eu}(I I I)$} & 1 & $5.83 \times 10^{-6}$ & $5.83 \times 10^{-6}$ & 7.76 & $9.22 \times 10^{-6}$ & $9.22 \times 10^{-6}$ & 7.80 \\
\hline & 2 & $3.54 \times 10^{-6}$ & $3.54 \times 10^{-6}$ & 8.00 & $2.97 \times 10^{-6}$ & $2.97 \times 10^{-6}$ & 8.03 \\
\hline & 3 & $6.30 \times 10^{-8}$ & $6.30 \times 10^{-8}$ & 8.08 & $3.69 \times 10^{-8}$ & $3.69 \times 10^{-8}$ & 8.08 \\
\hline & 4 & $4.17 \times 10^{-8}$ & $4.17 \times 10^{-8}$ & 8.12 & $1.05 \times 10^{-8}$ & $1.05 \times 10^{-8}$ & 8.13 \\
\hline & 5 & $5.67 \times 10^{-9}$ & $5.67 \times 10^{-9}$ & 8.09 & $2.80 \times 10^{-9}$ & $2.80 \times 10^{-9}$ & 8.17 \\
\hline
\end{tabular}


TABLE XIII

SORPTION RATIOS (ml/g) FOR YM-22-ISOTHERM STUDIES

\begin{tabular}{|c|c|c|c|c|c|c|c|c|}
\hline \multirow{2}{*}{$\begin{array}{l}\text { Solution } \\
\text { Number }\end{array}$} & \multicolumn{2}{|c|}{$\mathbf{s r}$} & \multicolumn{2}{|c|}{ Cs } & \multicolumn{2}{|c|}{$\mathbf{B a}$} & \multicolumn{2}{|c|}{$\mathbf{E u}$} \\
\hline & $\leq 75 \mu$ & 75-500 $\mu \mathrm{m}$ & $\leq 75 \mu \mathrm{m}$ & 75-500 $\mu \mathrm{m}$ & $\leq 75 \mu \mathrm{m}$ & $\underline{75-500 \mu \mathrm{m}}$ & $\leq 75 \mu$ & $75-500 \mu \mathrm{m}$ \\
\hline 1 & 20.3 & 9.43 & 11.9 & 10.1 & 400 & 211 & 5819 & 1140 \\
\hline 3 & 81.3 & 71.4 & 612 & 264 & 1220 & 795 & 1885 & 1890 \\
\hline 4 & 70.1 & 95.4 & 384 & 659 & 1270 & 594 & 891 & 1880 \\
\hline
\end{tabular}

As defined in Table XII.

TABLE XIV

SORPTION RATIOS ( $m \ell / g$ ) FOR YM-38-ISOTHERM STUDIES

\begin{tabular}{|c|c|c|c|c|c|c|c|c|}
\hline \multirow{2}{*}{$\begin{array}{l}\text { Solution } \\
\text { Number }\end{array}$} & \multicolumn{2}{|c|}{$\mathbf{S r}$} & \multicolumn{2}{|c|}{$\mathrm{Cs}$} & \multicolumn{2}{|c|}{$\mathbf{B a}$} & \multicolumn{2}{|c|}{ Eu } \\
\hline & $\leq 75 \mu \mathrm{m}$ & $75-500 \mu \mathrm{m}$ & $<75 \mu \mathrm{m}$ & $75-500 \mu \mathrm{m}$ & $\leq 75 \mu \mathrm{m}$ & $75-500 \mu \mathrm{m}$ & $\leq 75 \mu$ & 75-500 $\mu \mathrm{m}$ \\
\hline 1 & 1500 & 1190 & 3520 & 3440 & 103100 & 79420 & 7140 & 4590 \\
\hline 3 & 10300 & 9050 & 6340 & 4170 & 97500 & 35600 & 3690 & 1680 \\
\hline 4 & 10200 & 4110 & 2740 & 4020 & 81400 & 68700 & 3140 & 2670 \\
\hline
\end{tabular}




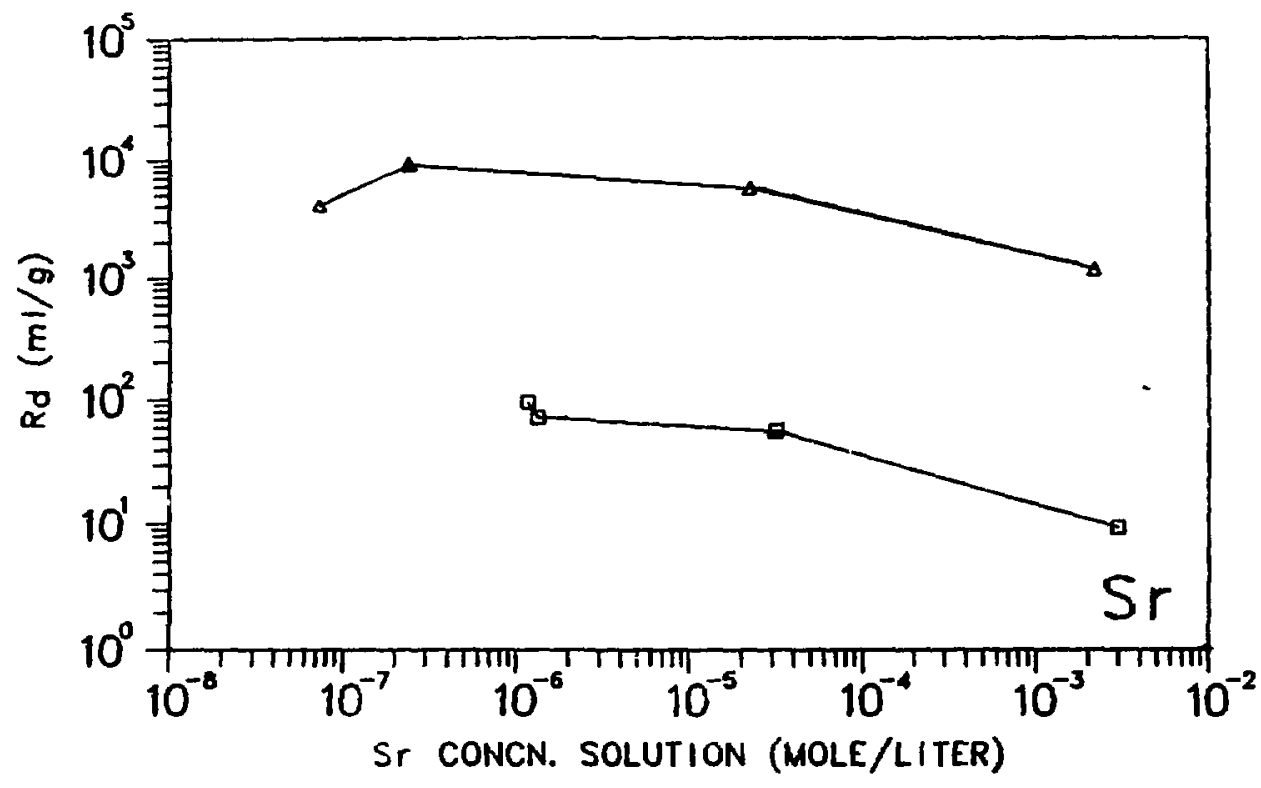
AMEIENT TEMFERATURE
$\begin{array}{ll}\square & Y M-22 \\ \Delta & Y M-38\end{array}$

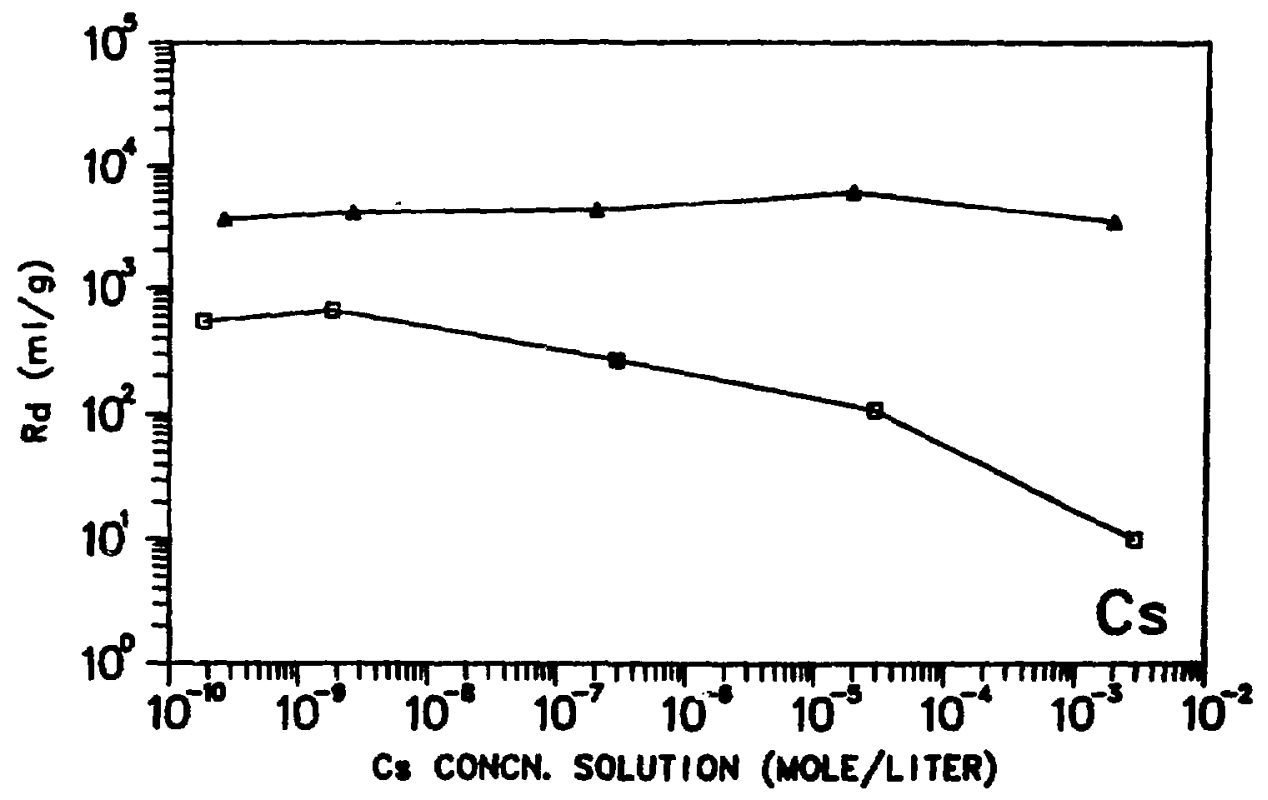

\section{5-500 $\mu \mathrm{m}$ AMBIENT TEMPERATURE \\ $\Delta \quad \begin{array}{r}Y M-22 \\ \Delta\end{array}$}

Fig. 1. Sorption ratios for strontium and cesium as a function of initial concentration in solution. 

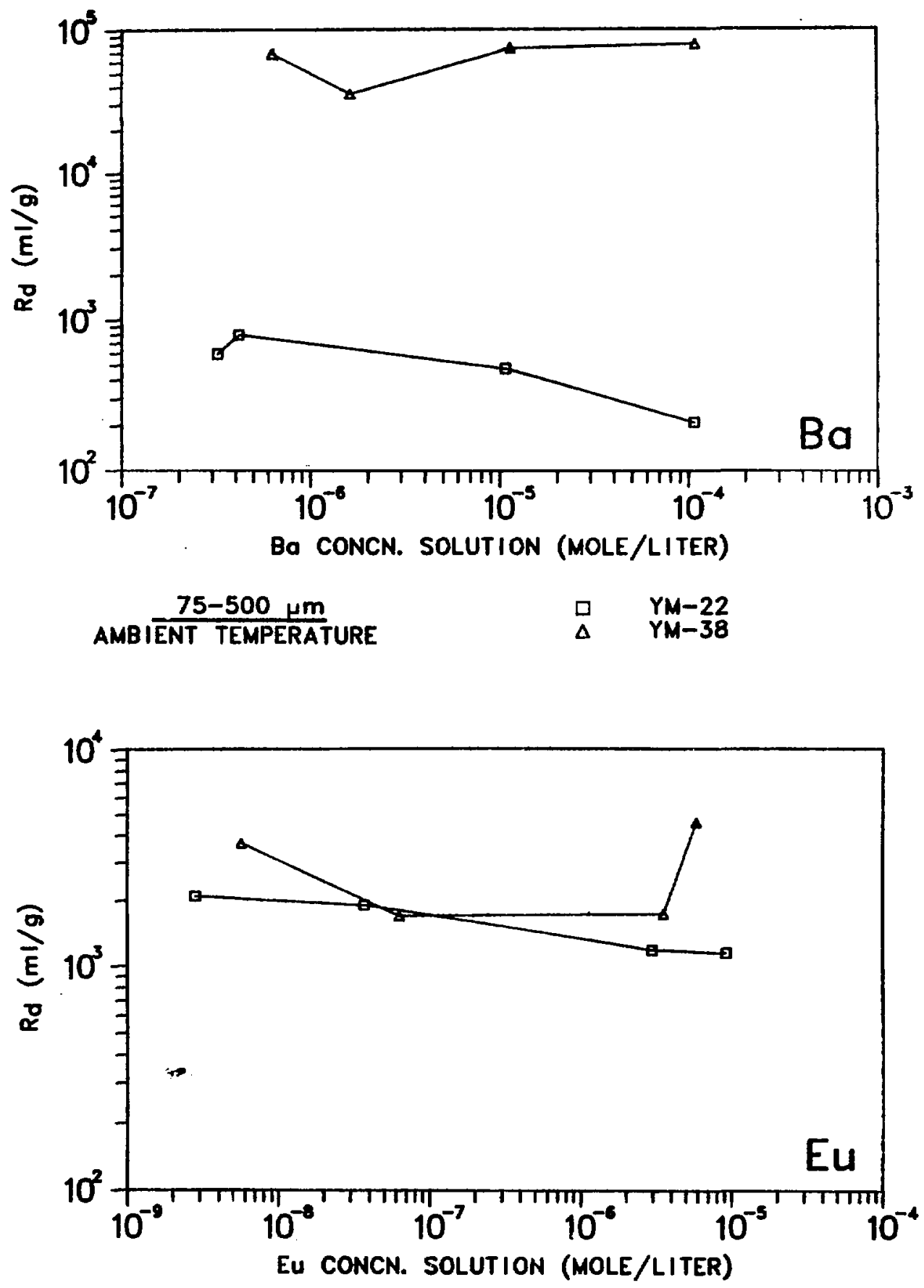

$$
\begin{array}{lll}
\frac{75-500 \mu M}{\mu M B I E N T} \text { TEMPERATURE: } & D & Y M-22 \\
\text { AMM-38 }
\end{array}
$$

Fig. 2. Sorption ratios of bariun and europiun as a function of initial concentration in solution. 
The sorption ratios for strontium, cesium, and barium (both fractions) and for europium (75- to 500- $\mu \mathrm{m}$ fraction) on tuff YM-22 increase slowly as the concentration of the element decreases. At the highest europium concentration, the sorption ratio for the $<75-\mu \mathrm{m}$ fraction is much higher than at the other concentrations. This might indicate precipitation or coprecipitation of europium. The control solution for this concentration, however, did not decrease in activity, which suggests that the high sorption ratio is not due to precipitation.

Sorption ratios for sample YM-38 do not vary regularly with concentration; it is possible that several different processes are taking place. Barium and europium sorption ratios are somewhat larger at the highest concentration, which might indicate some precipitation. The sorption ratios for all elements studied are smaller on tuff YM-22 (devitrified) than on tuff YM-38 (zeolitized) at all concentrations.

The concentrations in solution and on solids are represented on logarithmic scales in Figs. 3-6, and the same data are given in Tables XV and XVI. One way of representing sorption data ${ }^{15}$ is with the Freundlich equation $y=\mathrm{kc}^{\mathrm{n}}$, where $\mathrm{y}$ is the element concentration on the solid and $\mathrm{c}$ is the concentration in solution. This equation should result in a linear log-log plot of concentration in solution vs concentration on solid. The figures indicate that the simple Freundlich isotherms do not entirely describe the data. The nonlinearity of the data may be an artifact of the measurements because the actual concentrations of the elements on the solid were not measured.

A trend approaching a constant concentration on the solid with increasing concentration in solution may be a result of saturation of ion-exchange or other sorption sites on the solid. The opposite trend suggests that the limit of solubility may have been reached, resulting in onset of precipitation.

If, in spite of these difficulties, one fits the Freundlich isotherm equation to the data, the parameters given in Table XVII are obtained. For some applications this may be adequate. The values of $n$ for the M-38 (zeolitized) samples are all near unity. This is consistent with the obse vation that the sorption ratio $\left(R_{d}\right)$ is independent of concentration. The values of n for YM-22 (devitrified) samples are less than unity; that is, there is some dependence of sorption on elenent concentration. 


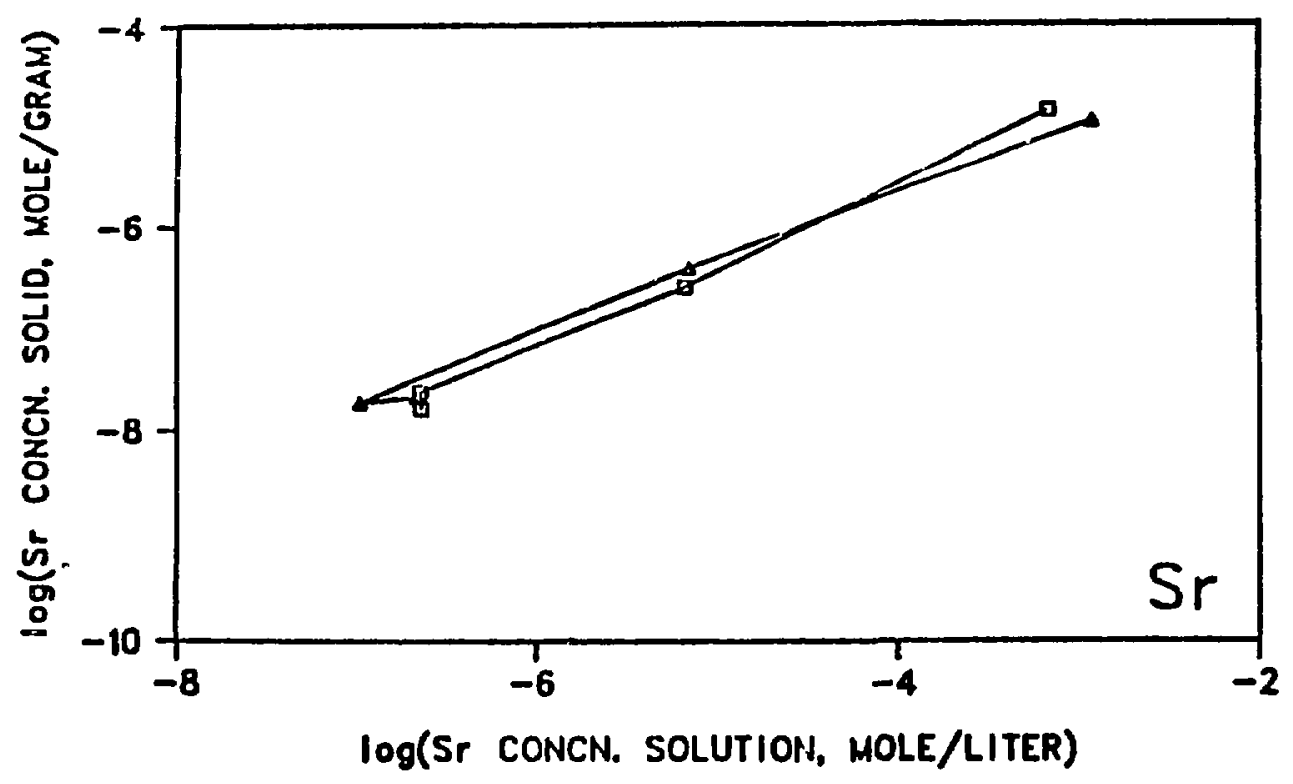
YUCCA MOUNTAIN TUFF YM-22 AMBIENT TEMPERATURE
D $\quad 75-50 \mathrm{~m} \mu \mathrm{mm}$

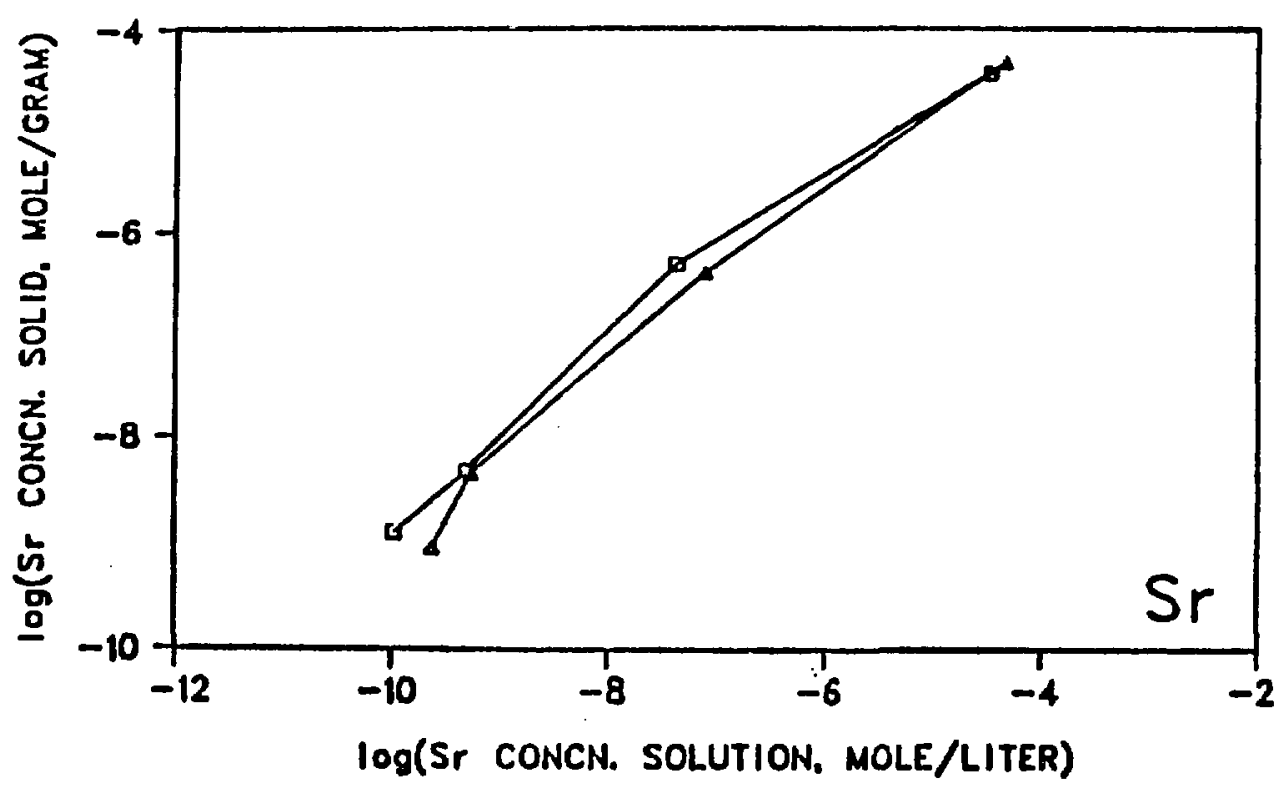

YUCCA MOUNTAIN TUFF YM-38 AMBIENT TEMPERATURE

ㅁ $\quad$ 75-50 ${ }^{\mathrm{mm}} \mathrm{mm}$

Fig. 3. Strontium sorption isotherms. 


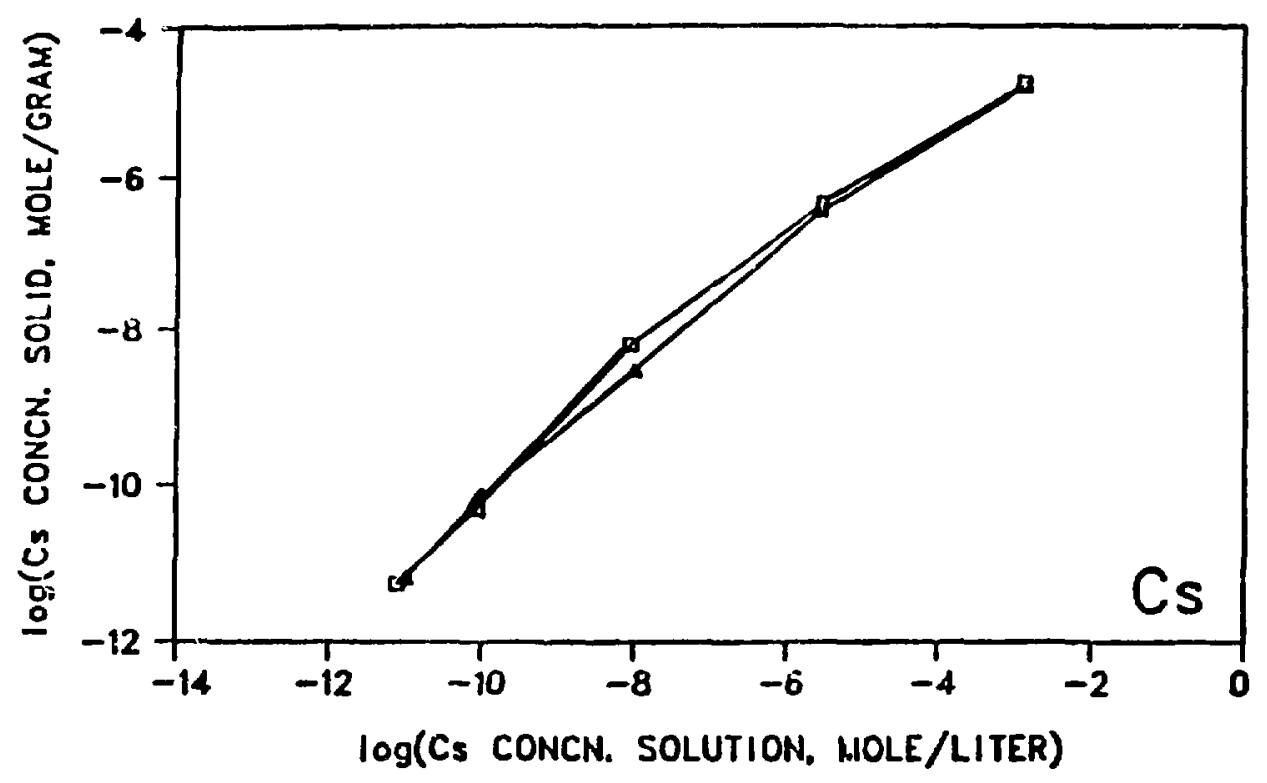

$\begin{array}{cl}\text { YUCCA MOUNTAIN TUFF YM-22 } & \text { D } \\ \text { AMBIENT TEMPERATURE } & \Delta 75 \mathrm{\mu m}\end{array}$

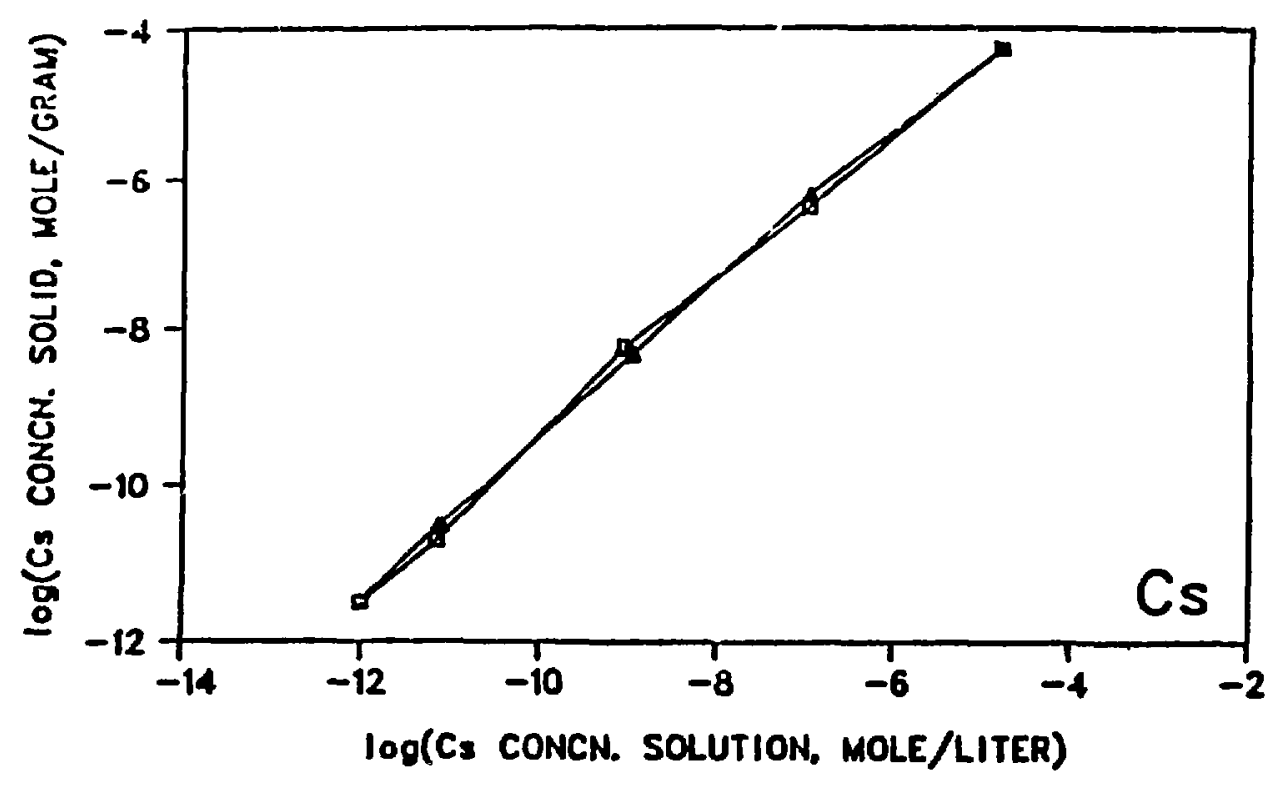

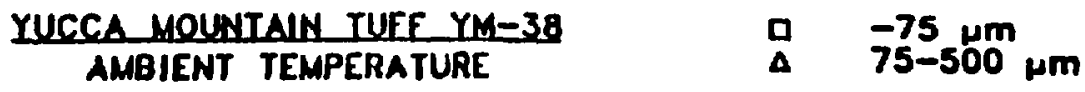

Fig. 4. Cesiun sorption isotherms. 

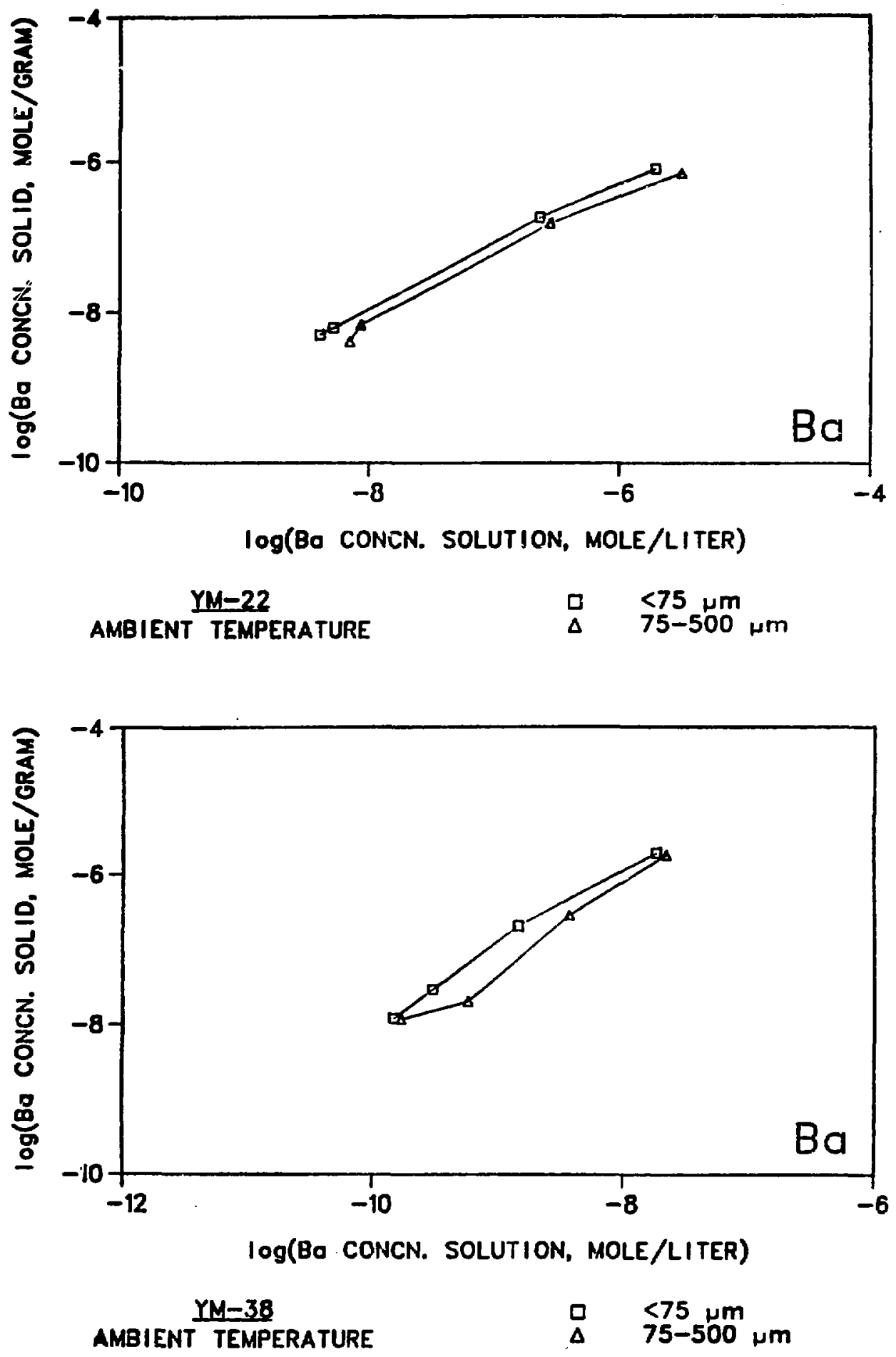

Fig. 5. Barium sorption isotherms. 

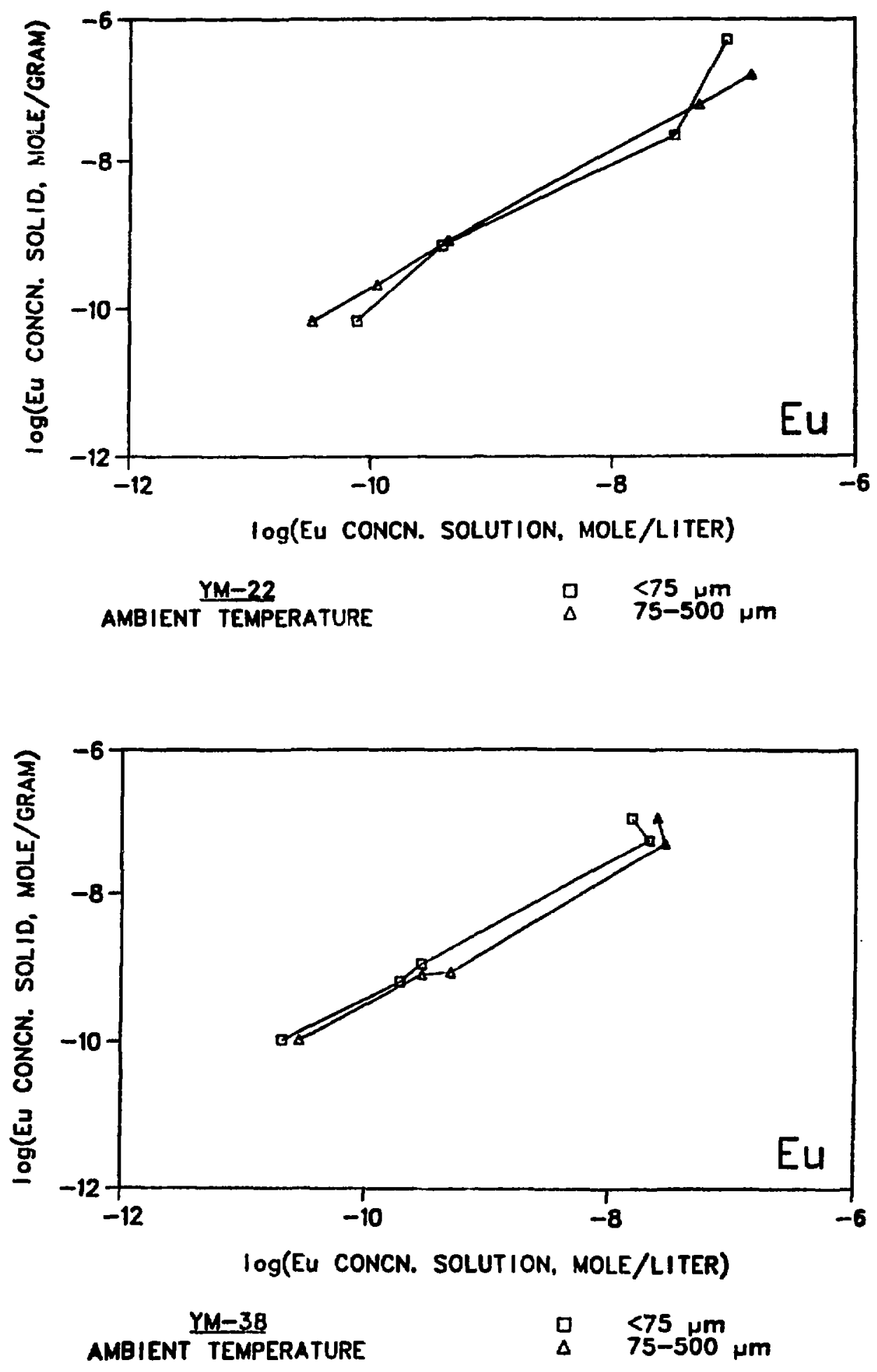

Fig. 6. Europiun sorption isotherms. 
TABLE XV

FINAL Sr, Cs, Ba, AND Eu CONCENTRATIONS

FOR ISOTHERM HEASUREMENTS ON YM-22

\begin{tabular}{|c|c|c|c|c|}
\hline \multirow[b]{2}{*}{ Element } & \multicolumn{2}{|c|}{$<75-\mu$ Fraction } & \multicolumn{2}{|c|}{$75-$ to $500-\mu \mathrm{m}$ Fraction } \\
\hline & Solution $^{a}$ & Solid $^{b}$ & $\underline{\text { Solution }}^{\mathrm{a}}$ & Solid \\
\hline \multirow[t]{4}{*}{ Sr } & 3.16 & 4.85 & 2.92 & 4.95 \\
\hline & 5.18 & 6.61 & 5.16 & 6.42 \\
\hline & 6.65 & 7.64 & 6.98 & 7.74 \\
\hline & 6.64 & 7.80 & 6.67 & 7.69 \\
\hline \multirow[t]{5}{*}{ Cs } & 2.87 & 4.74 & 2.85 & 4.79 \\
\hline & 5.52 & 6.37 & 5.54 & 6.46 \\
\hline & 8.05 & 8.21 & 8.00 & 8.53 \\
\hline & 10.06 & 10.31 & 10.05 & 10.18 \\
\hline & 11.10 & 11.26 & 10.97 & 11.18 \\
\hline \multirow[t]{4}{*}{ Ba } & 5.71 & 6.11 & 5.50 & 6.17 \\
\hline & 6.64 & 6.76 & 6.52 & 6.84 \\
\hline & 8.29 & 8.21 & 8.07 & 8.17 \\
\hline & 8.40 & 8.30 & 8.16 & 8.39 \\
\hline \multirow[t]{5}{*}{ Eu } & 7.05 & 6.29 & 6.85 & 6.79 \\
\hline & 7.48 & 7.65 & 7.28 & 7.21 \\
\hline & 9.41 & 9.14 & 9.36 & 9.08 \\
\hline & 10.12 & 10.17 & 9.95 & 9.68 \\
\hline & -- & -- & 10.49 & 10.17 \\
\hline
\end{tabular}

\footnotetext{
${ }^{a}$ The concentration in the solution is reported as the negative 108 (moles/l).

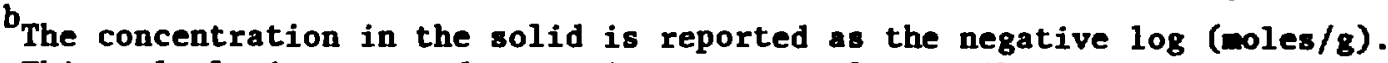
This calculation was made assuming no natural contribution.
} 
TABLE XVI

FINAL Sr, Cs, Ba, AND Eu CONCEHTRATIONS

FOR ISOTHERM MEASUREMENTS ON YM-38

\begin{tabular}{|c|c|c|c|c|}
\hline \multirow[b]{2}{*}{ Element } & \multicolumn{2}{|c|}{$<75-\mu a$ Fraction } & \multicolumn{2}{|c|}{ 75- to 500- $\mu$ m Fraction } \\
\hline & Solution $^{a}$ & Solid & Solution $^{a}$ & $\underline{\text { Solid }}^{\mathrm{b}}$ \\
\hline \multirow[t]{4}{*}{ Sr } & 4.46 & 4.42 & 4.34 & 4.31 \\
\hline & 7.37 & 6.32 & 7.11 & 6.40 \\
\hline & 9.30 & 8.33 & 9.26 & 8.35 \\
\hline & 9.97 & 8.91 & 9.62 & 9.05 \\
\hline \multirow[t]{5}{*}{$\mathrm{Cs}$} & 4.80 & 4.25 & 4.79 & 4.25 \\
\hline & 6.95 & 6.38 & 6.94 & 6.20 \\
\hline & 9.03 & 8.23 & 8.95 & 8.33 \\
\hline & 11.15 & 10.71 & 11.13 & 10.52 \\
\hline & 12.01 & 11.50 & 12.01 & 11.46 \\
\hline \multirow[t]{4}{*}{$\mathbf{B a}$} & 7.73 & 5.72 & 7.65 & 5.75 \\
\hline & 8.84 & 6.70 & 8.43 & 6.56 \\
\hline & 9.52 & 7.53 & 9.24 & 7.69 \\
\hline & 9.83 & 7.92 & 9.77 & 7.93 \\
\hline \multirow[t]{5}{*}{ Eu } & 7.82 & 6.96 & 7.61 & 6.95 \\
\hline & 7.68 & 7.27 & 7.55 & 7.32 \\
\hline & 9.30 & 9.08 & 9.30 & 9.08 \\
\hline & 9.53 & 9.11 & 9.53 & 9.11 \\
\hline & 10.54 & 9.98 & 10.54 & 9.98 \\
\hline
\end{tabular}

${ }^{a}$ The concentration in the solution is reported as the negative $\log ($ moles/l).

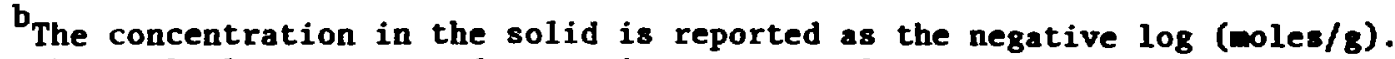
This calculation was made assuming no natural contribution. 
TABLE XVII

FREUNDLICH ISOTHERM PARAMETERS ${ }^{a}$

\begin{tabular}{|c|c|c|c|c|}
\hline $\begin{array}{l}\text { Rock } \\
\text { type }\end{array}$ & Fraction ( $\mu m)$ & Element & $\mathbf{n}$ & $-\log k$ \\
\hline \multirow[t]{8}{*}{ YM-22 } & $<75$ & Sr & 0.83 & 2.23 \\
\hline & & $\mathrm{Cs}$ & 0.80 & 2.17 \\
\hline & & $\mathbf{B a}$ & 0.83 & 1.34 \\
\hline & & $\mathbf{E u}$ & 1.1 & -1.20 \\
\hline & $75-500$ & Sr & 0.71 & 2.85 \\
\hline & & Cs & 0.79 & 2.34 \\
\hline & & $\mathrm{Ba}$ & 0.82 & 1.57 \\
\hline & & Eu & 0.92 & 0.46 \\
\hline \multirow[t]{8}{*}{ YM-38 } & $<75$ & Sr & 0.85 & 0.38 \\
\hline & & $\mathrm{Cs}$ & 1.0 & -0.66 \\
\hline & & $\mathrm{Ba}$ & 1.0 & -2.41 \\
\hline & & Eu & 1.1 & -1.0 \\
\hline & $75-500$ & Sr & 0.87 & 0.41 \\
\hline & & $\mathrm{Cs}$ & 1.0 & -0.65 \\
\hline & & $\mathbf{B a}$ & 1.1 & -2.50 \\
\hline & & $\mathbf{E u}$ & 0.98 & -0.29 \\
\hline
\end{tabular}

${ }^{a_{F r e u n d l i c h} \text { isotherm }} y=k c^{n}$, where $y$ is the concentration on the solid in moles/g and $c$ is the concentration in solution in moles/ 2 .

VIII. MIGRATION RATE STUDIES ON CRUSHED TUFF

\section{A. Measurements}

The migration of radionuclides through colunns of crushed tuff was studied. Samples from Jackass Flats Hole J-13 (JA-) and Yucca Mountain Drill Hole UE25a-1 (YM- ) were used in order to compare results with those obtained previously by batch sorption ratio $\left(R_{d}\right)$ measurements. The waters used for infiltration, the water delivery system, and descriptions of the columns themselves have been reported previously. 2

Each colum was characterized in terms of the total colum volume $V$ (the size of the colum calculated from colum dimensions), the free colum volume 
(FCV) (measured and used to calculate the effective column porosity), the dry bulk density, the particle size, and the flow rate.

The FCVs of approximately one-third of the columns studied were determined by use of both HTO and ${ }^{131} \mathrm{I}^{-}$. In the iodide case, the ${ }^{131} \mathrm{I}$ breakthrough (leading edge) curve and the rinse (trailing edge) were both used. There was essentially no difference in the values obtained with HTO or with $131_{I^{-}}$, and all measurements for a given column were averaged irrespective of the method used. For example, the FCV for a YM-54 column obtained with iodide (breakthrough) was $0.177 \mathrm{ml}$ and with HTO was $0.182 \mathrm{ml}$. On a MM-22 column, the iodide breakthrough method gave $0.249 \mathrm{ml}$, and the iodide rinse gave $0.239 \mathrm{ml}$.

Flow rates were determined by weighing the eluate sample delivered in a known time period. Upward-flow columns had relatively constant flow rates with a given syringe and pump setting, whereas gravity-flow columns tended to decrease in flow rate before a steady flow was established. Upward-flow rates generally ranged from 0.041 to $0.082 \mathrm{ml} / \mathrm{h}$. (A flow rate of $0.045 \mathrm{ml} / \mathrm{h}$ for a 2.1-cm-1ong by $0.5-\mathrm{cm}$-diam column with a free column volume of $0.224 \mathrm{ml}$ corresponds to an average mobile-phase velocity of $\sim 37 \mathrm{~m} / \mathrm{y}$. ) Flow rates were varied from 0.082 to $18 \mathrm{ml} / \mathrm{h}$ on three JA-32 tuff columns loaded with ${ }^{85} \mathrm{Sr}$. However, the fastest flow column was run with ${ }^{85} \mathrm{Sr}$ tracer added to the groundwater, rather than loaded onto the column in a spike.

The effect of the cesium ion concentration of tuff was also investigated. Two YM-54 columns were loaded with ${ }^{137} \mathrm{Cs}$ in 5 - to $15-\mu l$ spikes at a concentration of $\sim 10^{-9}$ M. Another YM-54 column was also run with a continuous feed of ${ }^{137} \mathrm{Cs}$ at a concentration comparable to that of the batch measurements, $\sim 10^{-9} \mathrm{M}$, to see if the $R_{d}$ value of cesium increased with decreased cesium ion concentration.

\section{B. Data Collection and Analysis}

General methods of sample collection, detection of radioisotopes, data analysis, and equations for calculation of retardation factors and corresponding distribution coefficients $\left(R_{d}\right)$ have previously been described. ${ }^{2}$ Sample collection techniques were modified for samples loaded simultaneously with ${ }^{131} I$ and ${ }^{237_{U}} \mathrm{U}$. Because the sorption ratios measured for $U(V I)$ are small, the retardation factors should also be small. With the colums used, the eluate volumes of interest required drop collection. A fraction collector (ISCO model 1200) and a colum were placed in a humidity box ("Manostat" glove box with the glove holes capped), 
in which $\sim 100 \%$ humidity was maintained in order to prevent evaporation of the drops before collection. Thin tubing $(0.15 \mathrm{~cm})$ connected the syringe pump to the column. The ${ }^{131} \mathrm{I}$ and ${ }^{237} \mathrm{U}$ on each planchet (1 drop) or in the scintillation vials were measured with a $\mathrm{Ge}(\mathrm{Li})$ detector.

Some difficulty was encountered due to the loss of iodide from the colunn effluent when it was dried in carrier-free form. Experiments showed that the $\mathrm{I}^{-}$ can be "fixed." Filter paper disks were punched to fit the botton of the planchets and were pretreated with $100 \mu \ell$ of $\mathrm{NaHSO}_{3}(\sim 1 \mathrm{mg})$ and $100 \mu \ell$ of $\mathrm{NaI}(\sim 2 \mathrm{mg})$ and then were air dried. After collection, $50 \mu l$ of $\mathrm{AgNO}_{3}(\sim 0.5 \mathrm{mg})$ was added to the paper disks, which were air dried again. These fixers made very stable samples that had good reproducibility.

\section{Results and Conclusions}

Sixteen columns of crushed tuff have been studied to date. Several kinds of elution behavior have been observed: (1) symmetric peaks where $50 \%$ of the activity eluted corresponds closely to the peak of the elution curve, (2) asymmetric peaks, and (3) "no peaks" - but instead a slow, usually uniform elution of activity. Plots of elution curves having symmetric and asymetric peak shapes have been given in Ref..2. With the exception of the JA-18*1 and YM-38\#1 tuff columns, the elution curves of ${ }^{85} \mathrm{Sr}$ fell into the first category, that is, symmetric peaks, with the column $R_{d}$ value being 1 to 3 times lower than the corresponding batch $R_{d}$ value. Three JA-32 colums were loaded with ${ }^{85} \mathrm{Sr}$ to compare the effect of varying the flow rate from $0.082 \mathrm{ml} / \mathrm{h}$ to $18 \mathrm{ml} / \mathrm{h}$. The effect of flow rate on the calculated distribution coefficients was negligible. However, as mentioned earlier, the fast-flow colunn was run with ${ }^{85} \mathrm{Sr}$ tracer added to the groundwater rather than loaded as a spike as were the slow-flowrate columns.

The YM-38\#1 column was loaded with ${ }^{85} \mathrm{Sr}$ before the batch $R_{d}$ measurement $(12000 \mathrm{~m} / \mathrm{g})$ was completed. None of the strontiun $\left(t_{\frac{1}{2}}=65.2\right.$ days) was eluted before the isotope decayed. A Polaroid film,exposed to the YM-38 column several months after elution was started, indicated that the ${ }^{85} \mathrm{Sr}$ remained in the top quarter of the colunn. Petrographic analysis of crushed rock from YM-38\#1, as wel1 as JA-32:1, was done both before and after elution. No change in YM-38 tuff was observed, but there was a slight alteration of feldspar in the JA-32 tuff (H. L. Sykes, Los Alawos, personal communication, May 1980). The JA-18\#1 colunn was the only other one loaded with ${ }^{85} \mathrm{Sr}$ for which 
a large batch $R_{d}$ value (16 $000 \mathrm{ml} / \mathrm{g}$ ) had been measured. The strontium on this column was eluted at a rate of $\sim 0.07 \%$ /day for $\sim 72$ days; then a smal1, sharp peak $\left(R_{d}=381 \mathrm{~m} \ell / \mathrm{g}\right)$ containing $9 \%$ of the total activity was observed. Elution of the JA-18\#1 column has continued for 95 days since the peak was observed, and the slow, uniform "leaking" has resumed. The JA-18 sample is a highly glassy tuff, and the slow elution may be due to a gradual dissolution of glass. This, however, would not explain the weak, sharp peak, which seems to indicate that more than one "sorption" mechanism exists. The JA-18\#1 and YM-38\#3 columns were also loaded with ${ }^{137} \mathrm{Cs}$, and the same slow leaking without a sharp peak was observed. Besides dissolution of glass, the slow elution of ${ }^{85} \mathrm{Sr}$ and ${ }^{137}$ is might also be the result of exchange of the sorbed radioactive species with stable isotopes in the pretreated waters used, which contain $\sim 10^{-9} \mathrm{M}$ cesium and $\sim 6 \times 10^{-7} \mathrm{M}$ strontium. Another column, JA-18\#3, has been started to see if the results obtained are reproducible.

Only two tuffs, YM-54 (three columns) and YM-22, have been analyzed to date in which elution of the ${ }^{137} \mathrm{Cs}$ activity occurred in a peak. The three MM-54 columns were run at two cesium concentrations, $10^{-6} \mathrm{M}$ and $10^{-9} \mathrm{M}$, to see if the $R_{d}$ value was affected by the cesium ion concentration. No effect was observed. On a JA-37 column, elution of ${ }^{137} \mathrm{Cs}$ began on day 95 , and the activity has increased from 25 to $500 \mathrm{dpm} / \mathrm{ml}$. In 184 days $3.6 \%$ of the total cesium has been removed.

Cesium-137 was loaded onto another YM-38 tuff column that was then run at a fast (4-5 m//h) flow rate. The ${ }^{137} \mathrm{Cs}$ was not detected until 1150 me had passed through the column. Fifty percent of the total ${ }^{137} \mathrm{Cs}$ was eluted in $7680 \mathrm{~m} \ell$ in slowly increasing amounts. (If the average flow rate used on the majority of columns had been used in this case, about 29 years would have been required to collect the total of 10.5 \& eluted.) Although a sharp peak was not observed and the expressions relating distribution coefficients with retardation factors are not appropriate for such cases, one can calculate a "lower limit" column $R_{d}$ value of $21900 \mathrm{~m} / \mathrm{g}$ from the volune required to elute $50 \%$ of the activity. This is a higher value than that observed from batch measurements $(8600 \mathrm{ml} / \mathrm{g}$ ), is indicative of the "complications" revealed by flow experiments, and is probably due in part to the fast flow rate used. All of the columns run to date with ${ }^{133}$ Ba have shown peaks, followed in some cases by a gradual elution of activity. The $R_{d}$ values calculated from the columns are 2.5 to 4.8 times lower than the corresponding batch $R_{d} v a l u e s$. 
Other isotopes studied were ${ }^{141} \mathrm{Ce}$ and ${ }^{237} \mathrm{U}$. The cerium loaded on a M-45 tuff column [batch $R_{d}$ of $730 \mathrm{ml} / \mathrm{g}$ (sorption), $5700 \mathrm{ml} / \mathrm{g}$ (desorption)] was not eluted in 165 days at a flow rate of $\leqq 1.020 \mathrm{m \ell} /$ day. Because the ${ }^{141} \mathrm{Ce}$ had decayed significantly in that period of time and the column could not be continued much longer, the flow rate was increased to $\leqq 0.6 \mathrm{m \ell} / \mathrm{h}$ until a total of $250 \mathrm{~m} \ell$ had been collected from the column. No ${ }^{141} \mathrm{Ce}$ was detected, indicating that the $R_{d}$ value is $>880 \mathrm{~m} / \mathrm{g}$; however, counting the whole column loaded with ${ }^{141} \mathrm{Ce}$, both before and after elution, indicated that $\sim 6 \%$ of the ${ }^{141} \mathrm{Ce}$ had been removed from the column. The YM-38\#2 column was run for 112 days at a flow rate of $0.911 \mathrm{ml} / \mathrm{day}$ with no ${ }^{141} \mathrm{Ce}$ detected in the eluate; it was stopped due to insufficient activity remaining on the column. The lower limit column $R_{d}$ was $>430 \mathrm{~m} \ell / \mathrm{g}$. Batch values were $830 \mathrm{~m} \ell / \mathrm{g}$ for sorption and $3800 \mathrm{ml} / \mathrm{g}$ for desorption. Another column, JA-18非, was loaded with ${ }^{141}$ Ce and also ${ }^{152} \mathrm{Eu}$. In 9 months a small amount of ${ }^{152} \mathrm{Eu}(\leqq 50 \mathrm{dpm} / \mathrm{m} \ell)$ was eluted. A tuff column, YM-54\#4, loaded with spikes of tritium, ${ }^{131} I$, and ${ }^{237} \mathrm{U}$ gave an $R_{d}$ value of $0.72 \mathrm{ml} / \mathrm{g}$ for uranium, compared with an average batch $R_{d}$ value of $1.5 \mathrm{~m} / \mathrm{g}$. The elution curves are shown in Fig. 7. The uranium peak was quite asymmetric, and the activity eluted per milliliter slowly decreased. Only $50 \%$ of the uranium activity had been eluted by drop 23 when most of the iodine had been eluted (Fig. 7). The marked asymetry may be an effect of the complicated sorption illustrated by the large difference between batch sorption $(1.5 \mathrm{ml} / \mathrm{g})$ and desorption $(11 \mathrm{ml} / \mathrm{g})$ ratios.

If a general conclusion can be stated from these observations, particularly from the data of ${ }^{85} \mathrm{Sr},{ }^{137} \mathrm{Cs}$, and ${ }^{133} \mathrm{Ba}$, it is probably that - except in the simplest of cases, where sorption coefficients are relatively low, and ionexchange equilibria not only exist but are the dominant mechanism for renoval of radioisotopes from solution -- the simple relation between the distribution coefficient $R_{d}$ or $K_{d}$ and the relative velocity of radionuclides with respect to groundwater velocity may be insufficient to permit accurate modeling of the retardation of radionuclides. This indicates the need to study the (probably many) mechanisms causing retardation, which could lead to an understanding of the relationship between the behavior in a dynanic laboratory experiment (and, ultimately, behavior in the field) and the many available batch $\mathbf{R}_{\mathbf{d}}$ data. 


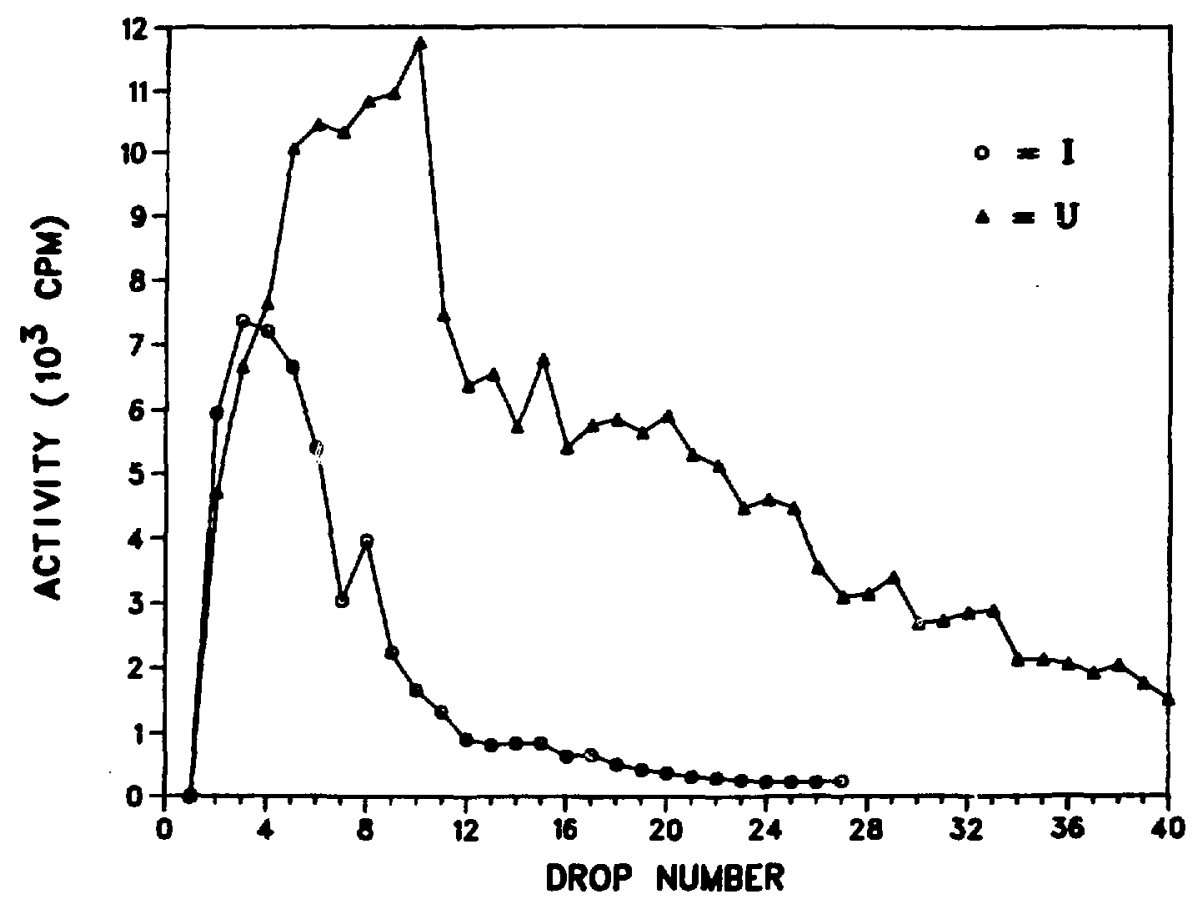

Fig. 7. Elution of ${ }^{131} \mathrm{I}$ and ${ }^{237} \mathrm{U}$ from a column of crushed tuff, YM-54.

IX. SORPTION MEASUREMENTS USING A CIRCULATING SYSTEM

It has been frequently observed that the sorption ratios determined by use of the batch technique increase slowly with contact time. Self-grinding of the crushed rock by the shaking used to agitate the phases is a possible cause of the increase. A series of experiments has been initiated to determine whether such self-grinding is responsible. A circulating system in which a 355- to 500- $\mu \mathrm{m}$ fraction of crushed rock is placed in a polycarbonate column ( $1.0 \mathrm{~cm}$ diam by $5.0 \mathrm{~cm}$ long) is being used. The appropriate groundwater is continuously circulated through the column in a closed loop as a substitute for shaking in the usual batch experiment. The columns have polyethylene bed supports and polypropylene Luer fittings on each end. A peristaltic pump (Pharmacia model $\mathrm{P}-3$ ) is used to produce flow rates of $\geq 0.6 \mathrm{ml} / \mathrm{min}$.

Experiments have been started with three crushed tuffs: JA-37, YM-22, and YM-54. Each uses the pretreated water appropriate for that tuff. The columns hold $\sim 4.5 \mathrm{~g}$ of rock, and the initial solution-to-solid ratio of the system was $\sim 20 \mathrm{ml} / \mathrm{g}$. First, the groundwater was circulated for 2 
months to check out the system and to pretreat the rock samples. Rock-pretreated groundwaters were then tagged with ${ }^{85} \mathrm{Sr},{ }^{137} \mathrm{Cs},{ }^{133} \mathrm{Ba},{ }^{141} \mathrm{Ce}$, and ${ }^{152} \mathrm{Eu}$ by the usual evaporation-dissolution procedure. Because the sorptive capacity of some of the components in the systems was unknown, groundwaters were circulated through similar systems without rock. Components of the system will be examined for activity at the conclusion of the experiments. Aliquots (5 ml) of the aqueous phases were removed at intervals of $4,7,9,12$, and 16 weeks. With ide removal of aliquots for counting, the solution-to-solid ratio changed $\sim \sim 3, g$ at the end of the experiment. Preliminary data are given in Tab. \& XTII. The time dependence observed in some of the batch studies does not $s$ em to be present in these studies, except for the earliest results for sa...ple YM-22. (No significant time 'dependence was observed in the batch studies with sampleF $Y M-22$ and $Y M-54$; the shortest contact times were 20 days in these batch e:-riments. ${ }^{2}$ ) The results from these circulating-column studies will be compared with those from batch studies and crushed-tuff columns in Sec. XIII.

\section{RADIONUCLIDE SORPTION AND TRANSPORT STUDIES WITH SOLID ROCK CORES}

Radionuclide sorption on rocks is principally a surface phenomenon; therefore, the surface condition is a critical parameter in experiments involving partitioning of radionuclides between solutions and geologic media. studies using crushed rock involve mineral surfaces newly exposed to the atmosphere and to water; those using geologic thin sections involve surfaces exposed and possibly altered by grinding and polishing. In an attempt to work with unaltered rock surfaces, we have initiated experiments in which pumped groundwater is used to move radionuclides through rock cores.

The intent of these experiments is to understand the transport of radionuclides through rock by either porous or fracture flow. These studies provide an intermediate step in the extrapolation from batch to in situ studies. Studies with granite cores are reported here, as well as those with tuff, because those studies contribute to the development of methodology and because of the possible similarity in flow patterns expected for welded tuff and granite.

The apparatus has been described previously. ${ }^{2}$ The rock cores are $15.9 \mathrm{am}$ high by 25.4-mm-diam right-circular cylinders. The confining pressure is usually 1000 psi. The groundwater used in these experiments is pretreated 
TABLE XVIII

Sr, Cs, AND Ba, SORPTION RATIOS

CIRCULATING COLUMNS

\begin{tabular}{|c|c|c|c|c|}
\hline \multirow[b]{2}{*}{ Sample } & \multirow{2}{*}{$\begin{array}{l}\text { Contact } \\
\text { Time (d) }\end{array}$} & \multicolumn{3}{|c|}{$R_{\mathrm{d}}(\mathrm{ml} / \mathrm{g})$} \\
\hline & & $\mathbf{S r}$ & $\mathrm{Cs}_{\mathrm{s}}$ & $\mathbf{B a}$ \\
\hline \multirow[t]{5}{*}{$\mathrm{YM}-22$} & 26 & 9.3 & 99 & 33 \\
\hline & 49 & 29 & 405 & 129 \\
\hline & 63 & 28 & 441 & 129 \\
\hline & 84 & 30 & 616 & 133 \\
\hline & 112 & 21 & 494 & 102 \\
\hline \multirow[t]{5}{*}{ YM-54 } & 26 & 39 & 105 & 111 \\
\hline & 49 & 53 & 158 & 153 \\
\hline & 63 & 49 & 131 & 146 \\
\hline & 84 & 44 & 112 & 132 \\
\hline & 112 & 41 & 99 & 116 \\
\hline \multirow[t]{5}{*}{$\mathrm{JA}-37$} & 26 & 401 & 1770 & 948 \\
\hline & 49 & 390 & 1890 & 819 \\
\hline & 63 & 398 & 1800 & 891 \\
\hline & 84 & 420 & 1920 & 729 \\
\hline & 112 & 365 & 1480 & 899 \\
\hline
\end{tabular}

with the appropriate crushed tuff, then centrifuged, and fiitered through a 0.05- $\mu \mathrm{m}$ membrane. Prior to the introduction of radionuclides to the rock cores, pretreated water is forced through the cores to pretreat the rock surfaces. This minimizes alteration of the rock during the experinent and hopefully better simulates the actual, in situ, conditions.

A. ${ }^{85}$ Sr in YM-22 Tuff

The movement of ${ }^{85} \mathrm{Sr}$ with water flowing through a core of $\mathrm{YM-22}$ tuff was observed. This tuff is devitrified and densely wilded and has relatively poor sorptive properties. The core was loaded with 20 , $\mu \ell$ of ${ }^{85} \mathrm{Sr}$ activity. Water was pumped through the core for a period of 12 months with an average 
flow rate of $0.8 \mathrm{~m} \ell /$ day. About $40 \%$ of the activity was eluted at a fairly constant rate; no peak was observed. The core was sectioned, and the residual activity was found to be relatively low in the top few millimeters of the core; it then increased to a peak in the core midsection, and remained high throughout the remainder of the core (Fig. 8). Based on the anticipated volume corresponding to elution of $50 \%$ of the activity, a crude estimate was made of the $R_{d}$ value for strontium on this $Y M-22$ core. The resultant value of $\sim 20 \mathrm{ml} / \mathrm{g}$ is less than the $53 \mathrm{ml} / \mathrm{g}$ value obtained from batch measurements ${ }^{2}$ but similar to those obtained with crushed-rock columns. 6 More elution and distribution profile studies of this type are planned after modifications in our experimental methodology are completed.

B. $241 \mathrm{Am}$ in YM-45 Tuff

The movement of ${ }^{241} \mathrm{Am}$ through a $\mathrm{YM}-45$ core was observed by monitoring the eluted solution and using microautoradiography on core slices. The column was run for 5 weeks with a flow rate of $0.8 \mathrm{ml} /$ day. Approximately $0.2 \%$ of the activity added to the column was collected.

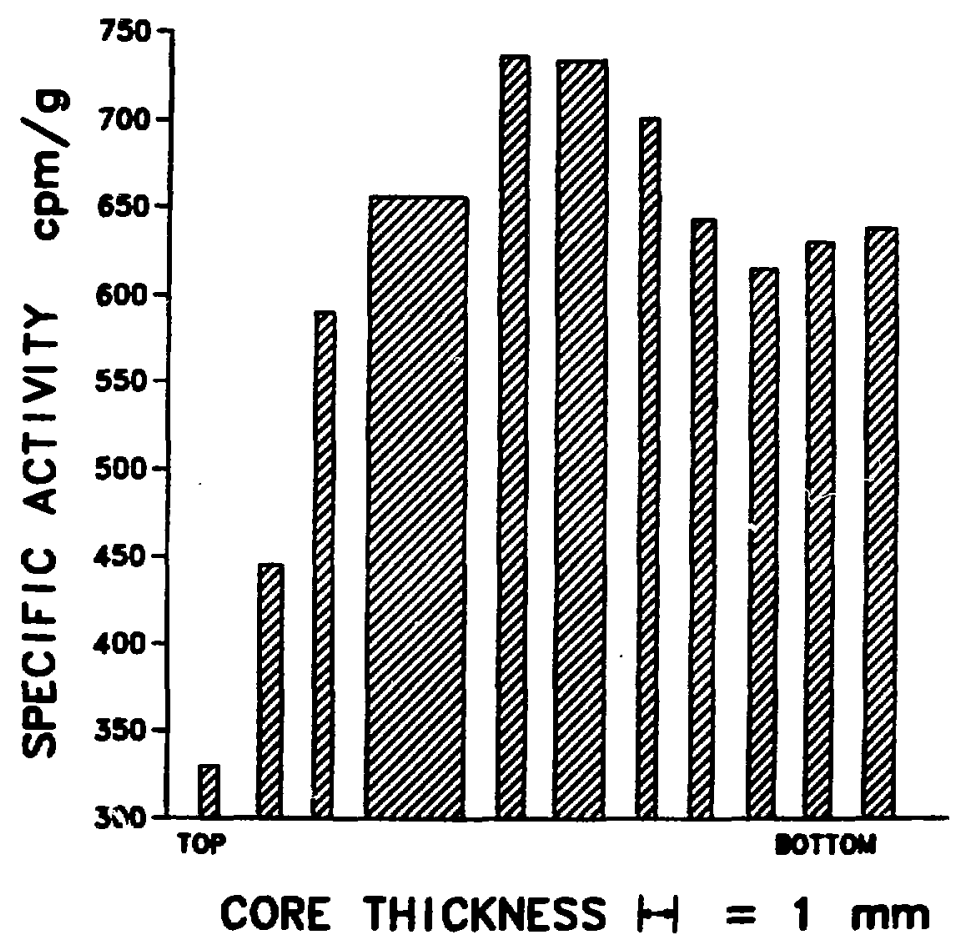

Fig. 8. Distribution of ${ }^{85}$ Sr activity in a solid core of YM-22 tuff. 
On disassembly of the pressure apparatus, it was found that the metal end cap in contact with the top surface of the core showed a high level of radioactivity and that the bottom end cap showed almost none. The activity on the core sides anj bottom was measured using microautoradiography. Low-tomoderate levels of activity were found on these surfaces. The ${ }^{241} \mathrm{Am}$ seemed to have been deposited primarily in an aggregated form, as a high ratio of stars to single tracks was observed in the autoradiographs. One giant colloid was observed on the bottom surface.

The core was then sectioned with a rock saw. Three slices about $1 \mathrm{~mm}$ thick were cut from the top of the core, and one slice was cut from the bottom of the core. The activity levels in these slices were measured with a NaI(TI) well crystal and an alpha proportional counter. The activity on the top surface of the core was $10^{3}$ to $10^{4}$ times greater than the activities on the bottom of the top slice and the other interior surfaces. The activities on the exterior surfaces and on the interior slice surfaces were compared using a collimator with the proportional counter. The exterior surfaces had activity levels greater by a factor of 5 then the interior surfaces. The activity on the exterior surface was relatively uniform, varying from region to region by only a factor of 2 .

The results of this experiment indicate that almost all of the activity originally placed on the top core face remained there. The small fraction of activity thac was mobilized by the water flow appears to have been deposited at higher concentrations on the exterior surfaces than in the interior of the core. This may imply that more flow occurred over these surfaces than through the core or that these surfaces were particularly sorptive. The observation that a large fraction of ${ }^{241}$ Am was in an aggregated form on the exterior surfaces, however, indicates that this portion of the activity probably did not flow through the core.

C. ${ }^{241}$ Am in Climax Stock Granite

Climax Stock granite core $C-79-5 b-1$ was placed in a Teflon sleeve and fractured using a hammer and chisel. The crack occurred along an old fracture plane extending through the core. After initial attempts to force water through the core failed, the two core segments were displaced axially and then returned to the initial configuration. A reasonable flow rate was then achieved. A solution containing ${ }^{241} \mathrm{Am}$ was placed on the top surface of the 
core at the crack. Water was pumped through the core for a period of 5 weeks with about $2 \%$ of the activity eluting.

On disassembly it was noted that both metal end caps showed extremely high levels of alpha activity. The whole core was counted in the NaI(T1) well counter and then sectioned with the rock saw. The first three slices from the top of the core and the first slice from the bottom shactered into six to eight fragments during the sawing operation. These were recovered and counted in the well counter. The activities of these slices are given in Table XIX.

The second slice from the bottom was zecovered intact and was coated with emulsion for examination with microautoradiography. The interior surfaces of the core midsection and of a ceconstructed mosaic of the second slice fron the top were examined using glass slides coated with Kodak ETB-3 emulsion that were placed in contact with the rock surfaces. The emulsions showed that a very large fraction of the activity was confined in the major crack system. Some activity was readily visible along the Teflon sleeve-core interface, especially in the regions where cracks reached the core surfaces. The tracks not in the vicinity of the cracks were mostly single with a few stars and were present in rather low density. No colloids were observed.

The exterior (curved) surface of the core midsection was monitored through a collimator with the proportional counter. The ends of the midsertion were coated with epoxy resin to facilitate handling and to prevent detection of alpha particles from the cut faces that were originally interior portions of the core. The surface activity at various angles of rotation of the core under the counter are shown in Table XX.

The counting data and microautoradiographs indicate that the ${ }^{241}$ Am was strongly concentrated in those regions that the solution could readily penetrate, namely, the major crack system and the exit line of the cracks at the core surface. Although the activity was distributed along the length of the core, the concentration in the topmost slice was about a factor of 3 higher than elsewhere. Less than $2 \%$ of the detected activity eluted from the core. It appears that the ${ }^{241}$ An was deposited primarily on those surfaces initially contacted by the solution introduced into the core. In addition to the activity on the surfaces near the cracks, there was significant activity on the other regions of the core surface, indicating exposure of these surfaces to the aqueous phase. 
TABLE XIX

${ }^{241}$ Am IN VARIOUS SECTIONS OF A CLIMAX STOCK CORE

\begin{tabular}{llc}
\multicolumn{1}{c}{ Slice } & Width & Activity $(\mathrm{cpm} / \mathrm{mm})$ \\
\hline 1st & $1 \mathrm{~mm}$ & $6.5 \times 10^{5}$ \\
2nd & $1 \mathrm{~mm}$ & $2.3 \times 10^{5}$ \\
3rd & $1 \mathrm{~mm}$ & $1.4 \times 10^{5}$ \\
Midsection & $8 \mathrm{~mm}$ & $2.0 \times 10^{5}$ \\
2nd from bottom & $1.5 \mathrm{~mm}$ & $1.3 \times 10^{5}$ \\
1st from bottom & $1.5 \mathrm{~mm}$ & $1.5 \times 10^{5}$
\end{tabular}

TABLE XX

${ }^{241}$ Am ACTIVITY VS ORIENTATION OF CORE SLICE

\begin{tabular}{crc}
$\begin{array}{c}\text { Degrees } \\
\text { of Rotation }\end{array}$ & $\begin{array}{r}\text { Alpha Activity } \\
(\mathrm{cpm})\end{array}$ & Comments \\
\cline { 2 - 3 } 45 & 187 & \\
90 & 5330 & Visible crack \\
135 & 82 & Visible crack \\
180 & 4290 & \\
225 & 56 & \\
270 & 1110 & \\
315 & 57 & \\
360 & 74 &
\end{tabular}

\section{Encased Cores}

The data in the preceding two experiments, as well as evidence from previous studies, ${ }^{2}$ strongly suggest that there can be leakage of pumped water between the Teflon sleeve and the core surface. For example, higher activity levels were sometimes found on the exterior surfaces of the core than on the interior surfaces of the core slices. Possible routes for this exterior flow were thought to be (1) leakage along the top surface between the end cap and the core and then down the core sides; and (2) flow from within the core to the side surfaces, then down the core sides. If the sorptive behavior of solid 
cores is to be compared with that of crushed-rock columns, it is imperative to be able to define with confidence the volume of rock exposed and the flow rate through this volume.

Experiments were performed to develop a method of completely encasing the cores in a material impermeable to water. A polyurethane and an epoxy were tested with and without confining pressure. Exploratory experiments, described below, were performed with groundwater and ${ }^{233} \mathrm{U}$ tracer. Because ${ }^{233} \mathrm{U}$ sorbs only weakly, the location of ${ }^{233} \mathrm{U}$ in the rock was used as an indicator of flow path.

The polyurethane was used in two experiments with YM-45 tuff. One core was given a thin coating on the curved surfaces and then inserted in a Teflon sleeve. The other was cast in a mold with both end caps; the polyurethane thickness was 4 to $8 \mathrm{~mm}$. The latter core was used with no confining pressure. The core with the thin coating was fitted with polyethylene washers and end caps, and a confining pressure of 5000 psi was imposed. The cores were treated with filtered, pretreated groundwater, and then ${ }^{233} \mathrm{U}$ was loaded on the top face of each core. Water was pumped through the cores under a pressure $\therefore: \sim 30 \mathrm{psi}$, which gave a flow rate of $\sim 1 \mathrm{ml} /$ day. Activity appeared in the eiuate after 2.5 to $3 \mathrm{ml}$ of water had passed through the cores, and the cores were then removed for analysis by microautoradiography. Substantial anounts of activity were found on the exterior surfaces of the core with the thin coating. It was not clear whether this was due to leakage fron the top (although the washer did appear to confine most of the activity placed on the top face), flow through surface areas not completely coated with the polyurethane, or simply penetration by alpha particles of the very thin coating. The rock with the thick coating showed no leakage around the end caps, and the rock-to-resin bonds seemed to have maintained their integrity. Some variation in the activity levels near the rock surfaces was observed.

Several granite cores were encased in epoxy by casting in a mold, and the epoxy pottings were tested for their ability to withstand pressure. One core was fitted with end pieces having a polished surface, and another with end caps that had been sand blasted. These were attached to the high-pressure column apparatus, and the pumping pressure was gradually increased; no confining pressure was employed. Both epoxy coatings held overnight at a pressure of 360 psi. A third granite core was placed under a confiring pressure of up to 5000 psi with no leaks occurring. The confining pressure was dropped to 
2000 psi, and a gradually increasing pumping pressure was imposed. The maximum imposed pressure of $880 \mathrm{psi}$ was held for a period of 3 days with no leakage.

Several different types of rock cores were examined using ${ }^{233} \mathrm{v}$ tracer to determine the activity distribution in the core at the point at which the activity was just beginning to elute. Of particular concern were the extent of penetration of the epoxy into the core (which might inhibit the water flow) and the possibility that the activity might concentrate in regions containing the epoxy.

A core of YM-54 tuff was coated with epoxy and loaded with ${ }^{233} \mathrm{U}$. After $3 \mathrm{~m} \ell$ of water had been collected over a 2 -day period, ${ }^{233} \mathrm{v}$ was observed in the eluate and pumping was stopped. With the aid of a small rock saw, the end caps were removed, and the core was sliced into several sections. Surface activity, as measured with a proportional counter and by autoradiography, revealed that most of the ${ }^{233} \mathrm{U}$ had penetrated only about $5 \mathrm{~m}$ down into the core. Within this region of penetration, there was not much spreading of activity toward the perimeter of the core. At the top face of the core, the activity had been confined largely to the area in the center of the washer. Some penetration of washer-rock and washer-end cap interfaces was indicated, and the activity levels on both surfaces of the washer were appreciable. At a depth of $4.7 \mathrm{~mm}$, most of the activity was still concentrated in the center of the core. This flow pattern is in marked contrast to that previously observed for a JA-26 tuff core in which the activity was distributed uniformly below a depth of a few millimeters, showing no concentration gradients across the face of the core slices.

A granite core, C-79-9b-1, which had been coated with epoxy and tested for leaks under confining pressure, was treated with ${ }^{233} \mathrm{U}$ in an experiment similar to that described above for the YM-54 tuff. A punping pressure of about $880 \mathrm{psi}$ and a confining pressure of $2000 \mathrm{psi}$ for a period of 1 day gave an eluted volume of 0.1 ne that contained about $3 \%$ of the initial $10^{6}$ cpm of activity introduced onto the top of the core. As in previous experiments, the polyethylene washer confined most of the activity to the top center of the core face; however, this pattern of activity was not maintained into the core. The activity levels on the interior surfaces of slices taken through the core were very low. A systew of cracks over about $25 \%$ of the slice area seemed to be responsible for $₫ 11$ of the flow through a slice taken 
about 3 from the top face of the core. Similarly, the top side of the bottom slice had activity confined to two saall areas; however, on the bottom of this slice (the bottom exterior of the core), the activity level was nearly as high as on the top surface of the core. Likewise, the bottom end cap was found to have nearly $60 \%$ as much activity as the top end cap. This would seem to indicate that a "reservoir" of radioactive solution accumulated at the bottom face of the core, perhaps with the bottom washer inhibiting clean elution from this area. In neither the tuff nor the granite core was there any indication that the epoxy had penetrated appreciably into the core, nor were there regions of high track density near the core-epoxy interface.

\section{REDOX POTENTIAL OF GROUNDWATERS}

The redox potential (Eh) of a natural groundwater-rock system may be oxidizing or reducing. Consequences of oxidizing or reducing conditions were discussed in Sec. I. In this section we discuss the initial investigations of the measurement and control of the oxidation-reduction potential of rockgroundwater systems in the laboratory. Either platinum or gold electrodes, referenced to a standard calonel electrode, are currently being used to measure Eh. Standards of +430 and $-388 \mathrm{mV}$ relative to the normal hydrogen electrode are used to calibrate the electrodes. Both a potentiostat and reducing agents or buffers will be used to obtain the desired potentials.

Measurements of Eh on unpoised or complex systems are difficult to interpret. 16 A weak signal can be undetectable because of electrical noise in the system. Measurements in our laboratory of both aerated and oxygen-free groundwaters in the absence or presence of many of the samples studied (Climax Stock granite, Eleana argillite, and sowe of the tuffs) have mostly shown positive potentials. However, mixtures of pulverized MM-54 (devitrified) or YM-38 (zeolitized) tuff samples and water from Well J-13 that have been shaken in the controlled atmosphere for more than 1 year show slightly lower Eh values, -20 to $-140 \mathrm{wV}$, compared to the values of +300 to $+350 \mathrm{mV}$ for aerated solutions at pH values of about 8 .

Hydroxylamine hydrochloride was examined as a reducing agent. Solutions were sparged with nitrogen gas for several hours to rewove some of the oxygen, $\mathrm{MH}_{2} \mathrm{OH} \cdot \mathrm{HCl}$ was added, and the $\mathrm{pH}$ was adjusted to neutral or slightly basic with dilute NaOH. The Eh was measured as a function of $\mathrm{pH}$. An approximately 
linear correlation was found. At $\mathrm{pH} 7, \mathrm{Eh} \cong+120 \mathrm{mV}$, and at $\mathrm{pH} 10.8$, $E h \cong-130 \mathrm{mV}$.

Nile Blue $\left(10^{-6} \mathrm{M}\right)$ in a sodium carbonate solution $\left(10^{-3} \mathrm{M}\right)$ was used in a preliminary experiment of Eh control. Ferrous ion was necessary to reduce the Eh to the Nile Blue theoretical value of $-160 \mathrm{mV}$ at $\mathrm{pH} 8.3$. This reading was maintained for several hours with the addition of ferrous ammonium sulfate. ottaway ${ }^{17}$ states that concentrations of $\leqq 10^{-7} \mathrm{M}$ Nile Blue are needed for true solution behavior.

A potentiostat cell similar to those of Harrar ${ }^{18}$ and Rai et al. ${ }^{19}$ has been fabricated. The Teflon cell is $3.6 \mathrm{~cm}$ in diameter and $7.5 \mathrm{~cm}$ in height. The working electrode is a 3.3-cm-diam, platinum-gauze cylinder. The counter electrode is a folded 5- by 2-cm platinum gauze isolated in a glass cell with a porous Vycor frit making contact with the solution. A salt bridge contains a calomel reference electrode. Inlet and outlet tubes for inert-gas sparging and a sample port with stopper are included. The potentiostat will be used to reach various desired potentials. For long-term experiments, a study is being made of the use of Eh buffers or moderators to maintain a particular potential after it is obtained by the potentiostat.

H. Taube (Stanford University, personal communication, 1980) has suggested Osmium(II-III) complex couples to buffer the Eh. Ottaway ${ }^{17}$ discussed organic redox indicators in the applicable range. Possible moderators are listed in Table XXI, with the corresponding $\mathrm{E}_{\mathrm{m}}^{7}$ (defined as the formal potential at $\mathrm{pH} 7$ ) values and the $\mathrm{pH}$ range under which they were investigated.

If it is determined that the buffer does not interfere with sorption, then the method will be applied for studying sorption of elements such as plutonium, uranium, technetium, and neptunium under both controlled-atmosphere and controlled-Eh conditions.

\section{MATERIALS CHARACTERIZATION}

Sorption and transport of nuclides in geologic media are dependent on the nature of both the groundwater and the rock. Changes in the groundwater as it moves through various types of rock may affect sorptive properties; therefore, it is necessary to adequately characterize the rocks and waters studied in the laboratory. Characterization includes determination of concentrations of major and minor elements and measurement of oxidation states of elements that may exist in several states in both the waters and the rocks as 
TABLE XXI

POSSIBLE Eh MODERATORS

\section{Inorg.-Aj.c Ccuples}

$E_{m}^{7}(V)$

pH range

$$
\begin{array}{ll}
\text { Os(II) - Os (III) couples } & \\
\text { tris (1,10-phenonthroline) } & 0.88 \\
2,2^{\circ} \text {-bipyridine } & 0.88 \\
\text { dicyano-bis-(2,2'-bipyridine) } & 0.78 \\
\text { 4,7-dimethylphenanthroline } & 0.68-0.73 \\
3,4,7,8 \text {-tetramethylphenanthroline } & 0.68-0.73 \\
\text { Co(II) - Co(III) sepulchrate } & -0.3
\end{array}
$$

\section{Organic Couples}

Bindschedler's Green

$$
\begin{aligned}
& 0.224 \\
& -0.299 \\
& -0.281 \\
& -0.253 \\
& -0.446^{a} \\
& -0.125 \\
& -0.034
\end{aligned}
$$$$
2-9.5
$$

Induline Scarlet$$
3.0-8.6
$$

Rosinduline 2G

Lissamine Bue BF

$4.8-11.4$

$\mathrm{N}, \mathrm{N}^{\circ}$-dimethy1 viologens

Indigo Carmine

$1-11$

Pyocyanine

\footnotetext{
${ }^{a}$ Potentials of substituted viologens are independent of $\mathrm{pH}$ and follow the simple Nernst equation $E h=E_{0}+(R t / F) \ln \left(C_{0} / C_{r}\right)$.

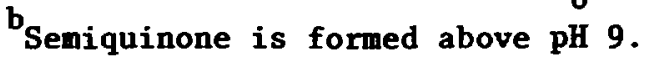

well as the mineralogy-petrology of the rock. Some of these measurements are given in this section.

\section{A. Water Composition}

Water from We11 J-13 was pretreated for a minimum of 2 weeks with crushed tuff from each of the cores studied from Hole UE25a-1. The sorption measurements with cores YM-22, MM-38, YM-45, YM-48, YM-49, and YM-54 were reported previously. ${ }^{2}$ Anslyses of these waters are reported here together with analyses of waters prepared with cores $\mathrm{YM-5,}$ YM-30, YM-42, and YM-46. The water prepared by pretreatment with each of these cores was sent to the USGS for analysis. These results are given in Table XXII. The composition of Well 
TABLE XXII

WELL J-13 TUFP-PRETREATED WATERS ${ }^{a}$

\begin{tabular}{|c|c|c|c|c|c|c|c|c|c|c|c|c|}
\hline \multirow[b]{2}{*}{ Anelysis } & \multicolumn{2}{|c|}{$\mathrm{YH}-54$} & \multicolumn{2}{|c|}{ YII-38 } & \multirow[t]{2}{*}{$M_{M-5}$} & \multirow[t]{2}{*}{ MI-22 } & \multirow[t]{2}{*}{$\mathrm{M}-30$} & \multirow[t]{2}{*}{ YM-42 } & \multirow[t]{2}{*}{ YH-45 } & \multirow[t]{2}{*}{ YM-46 } & \multirow[t]{2}{*}{ YM-48 } & \multirow[t]{2}{*}{ YM-49 } \\
\hline & Air & $\mathrm{CA}^{\mathrm{b}}$ & Air & $\mathrm{CA}^{\mathrm{b}}$ & & & & & & & & \\
\hline Beriun & 0.03 & 0.2 & 0.1 & 0.2 & 0.03 & 0.1 & 0.1 & 0.08 & 0.02 & 0.09 & 0.02 & 0.09 \\
\hline Calcium & 14 & 13 & 14 & 13 & 15 & 13 & 14 & 15 & 14 & 15 & 18 & 20 \\
\hline Chloride & 6.8 & 6.5 & 7.5 & 6.6 & 7.9 & 7.3 & 7.0 & 6.9 & 6.8 & 7.5 & 6.7 & 6.9 \\
\hline Fluoride & 2.6 & 2.5 & 2.5 & 2.6 & 2.5 & 2.6 & 2.5 & 2.4 & 2.5 & 2.5 & 2.5 & 2.5 \\
\hline Iron & 0 & $<0.01$ & 0.01 & 0.01 & $<0.01$ & $<0.01$ & $<0.01$ & 0.04 & 0.04 & 0.02 & 0.03 & 0.03 \\
\hline Lithium & 0.06 & 0.05 & 0.05 & 0.05 & 0.04 & 0.05 & 0.05 & 0.05 & 0.06 & 0.05 & 0.06 & 0.06 \\
\hline Hagnesium & 1.4 & 1.8 & 0.1 & 0.3 & 4.1 & 2.4 & 1.5 & 0.5 & 1.2 & 1.1 & 1.2 & 1.2 \\
\hline Hanganese & 0.001 & 0.001 & $<0.001$ & $<0.001$ & $<0.001$ & $<0.001$ & $<0.001$ & $<0.001$ & 0.01 & 0.002 & 0.03 & 0.002 \\
\hline Potassiun & 5.9 & 5.3 & 5.8 & 5.8 & 8.2 & 5.3 & 2.5 & 2.2 & 5.6 & 3.9 & 2.5 & 2.6 \\
\hline Silica & 74 & 66 & 63 & 71 & 70 & 68 & 60 & 56 & 68 & 67 & 74 & 71 \\
\hline Sodium & 56 & 52 & 57 & 56 & 51 & 54 & 53 & 59 & 53 & 51 & 50 & 49 \\
\hline Strontiun & 0.04 & 0.04 & 0.003 & 0.003 & 0.25 & 0.10 & 0.15 & 0.009 & 0.04 & 0.03 & 0.03 & 0.03 \\
\hline Sulfate & 24 & 23 & 26 & 23 & 23 & 24 & 23 & 27 & 24 & 24 & 24 & 25 \\
\hline
\end{tabular}

$\begin{array}{llllllllllllll}\text { pH } & 8.3 & 8.7 & 8.4 & 8.7 & 8.2 & 8.3 & 8.2 & 8.2 & 8.3 & 8.2 & 8.3 & 8.1\end{array}$

Concentrations are in $\mathrm{g} / \mathrm{l}$. Unlese specified all waters were pretreated in air.

${ }^{b} \mathrm{CA}$ refers to the controlled stmosphere: $\mathrm{H}_{2}$ with $\leq 0.2 \mathrm{ppm} \mathrm{O}_{2}, \leq 20 \mathrm{ppm} \mathrm{CO}_{2}$. 
J-13 water has been given previously (see, for example, Ref. 1); it did not change significantly on addition of any of the crushed rock from Hole UE25a-1.

In order to determine whether additional changes in water composition would occur with longer exposures to the crushed rock, two tuffs were kept in contact with the well water for periods as 10 g as 256 days (YM-30) and 131 days $(\mathrm{JA}-26)$. The water treated with YM-30 tuff changed very little with time, whereas that treated with JA-26 tuff changed significantly, especially in concentration of iron. However, the analyses of water treated with JA-26 tuff for 131 days were made on turbid solutions and are probably not reliable. Repeated centrifuging and filtering of the water through $0.45-\mu \mathrm{m}$ Millipore filters did not help to clear the turbid, reddish-brown water. Data obtained with the direct current, plasma-source, emission spectrometer are given in Table XXIII.

\section{B. Determination of $\mathrm{Fe}$ (II) in Silicate Rocks}

The presence of $\mathrm{Fe}$ (II) and $\mathrm{Fe}$ (III) has important effects on the oxidation potential in geological systems. Total iron can easily be determined. However, a good method for determination of Fe(II) in silicate rocks must involve careful techniques to keep the Fe(II) from oxidizing during preparation, dissolution, and analysis. In most procedures, hydrofluoric acid is used; this restricts the container composition. The method that we have selected is based on a procedure ${ }^{20}$ in which the silicate rock is dissolved with the simultaneous oxidation of $\mathrm{Fe}$ (II) with ICl to form $\mathrm{I}_{2}$. The $\mathrm{I}_{2}$ is immediately extracted into carbon tetrachloride, which is present in the dissolving vessel, and then determined by titration with standardized $\mathrm{KIO}_{3}$ solution, keeping the carbon tetrachloride from contact with air. Iodine monochloride has a lower oxidation potential than either permanganate or dichromate. The use of ICl as oxidant precludes interference by Mn(II) or Cr(III). The pertinent half-cell reactions are

$$
\begin{array}{ll}
\mathrm{MnO}_{4}{ }^{-}+8 \mathrm{H}^{+}+5 \mathrm{e}^{-}=\mathrm{Mn}^{2+}+4 \mathrm{H}_{2} \mathrm{O} & \mathrm{E}^{\circ}=+1.52 \mathrm{~V}, \\
\mathrm{Cr}_{2} \mathrm{O}_{7}^{2-}+14 \mathrm{H}^{+}+6 \mathrm{e}^{-}=2 \mathrm{Cr}^{3+}+7 \mathrm{H}_{2} \mathrm{O} & \mathrm{E}^{\circ}=+1.33 \mathrm{~V}, \\
\mathrm{MnO}_{2}+4 \mathrm{H}^{+}+2 \mathrm{e}^{-}=\mathrm{Mn}^{2+}+2 \mathrm{H}_{2} \mathrm{O} & \mathrm{E}^{\circ}=+1.23 \mathrm{~V},
\end{array}
$$




$$
\begin{array}{ll}
2 \mathrm{I}^{+}\left(\mathrm{Cl}^{-}\right)+2 \mathrm{e}^{-}=\mathrm{I}_{2}+2 \mathrm{Cl}^{-} & \mathrm{E}^{\circ}=+1.19 \mathrm{~V}, \text { and } \\
\mathrm{Fe}^{3+}+\mathrm{e}^{-}=\mathrm{Fe}^{2+} & \mathrm{E}^{0}=+0.77 \mathrm{~V}
\end{array}
$$

The method described above has been modified and tested on several USGS "standard" rocks. The results (Table XXIV) usually agree within $2 \%$ of the stated $\mathrm{Fe}$ (II) concentration.

No $\mathrm{Fe}$ (II) was detectable in $\mathrm{YM}-22$, YM-38, and $\mathrm{YM}-46$ tuffs. The linit of detection by the present method is $\sim 0.2 \%$.

C. Determination of $\mathrm{Fe}$ (II) in Groundwater

Knowledge of concentration ratios of members of redox pairs such as $\mathrm{Fe}$ (II)/Fe(III) in groundwaters and solutions that have been pretreated with rocks under various conditions is necessary to understand the redox potential of the waters, to interpret the sorption results for multivalent elements, and to complement electrode Eh measurements. A method modified from that of Lee and Stumm ${ }^{21}$ is being used to determine the $\mathrm{Fe}$ (II) concentration. The

TABLE XXIII

\begin{tabular}{|c|c|c|c|c|c|c|}
\hline \multirow[b]{2}{*}{ Element } & \multicolumn{3}{|c|}{$\mathrm{YM}-30(\mathrm{mg} / \mathrm{l})$} & \multicolumn{3}{|c|}{$\mathrm{JA}-26(\mathrm{mg} / \mathrm{l})$} \\
\hline & $42 \mathrm{~d}$ & $51 \mathrm{~d}$ & $256 \mathrm{~d}$ & $14 \mathrm{~d}$ & $52 \mathrm{~d}$ & $131 \mathrm{~d}$ \\
\hline $\mathrm{Mg}$ & 2.08 & 2.03 & 2.09 & 1.29 & 1.90 & 1.83 \\
\hline Mn & 0.72 & 0.58 & 0.73 & 0.170 & 0.073 & 0.321 \\
\hline $\mathbf{S i}$ & 45.4 & 40.6 & 42.5 & 48.0 & 45.0 & 67.9 \\
\hline $\mathrm{Fe}$ & 0.194 & 0.145 & 0.100 & 0.185 & 0.296 & 4.99 \\
\hline $\mathbf{S r}$ & 0.205 & 0.173 & 0.176 & 0.077 & 0.078 & 0.64 \\
\hline $\mathbf{B a}$ & 0.147 & 0.096 & 0.153 & 0.235 & 0.231 & 1.34 \\
\hline $\mathbf{v}$ & 0.049 & 0.037 & 0.038 & 0.037 & 0.043 & 0.061 \\
\hline $\mathrm{Ti}$ & 0.087 & 0.041 & 0.059 & 0.047 & 0.068 & 0.226 \\
\hline $\mathrm{Ca}$ & 19.1 & 17.0 & 17.7 & 11.3 & 13.9 & 5.92 \\
\hline $\mathrm{Li}_{\mathbf{i}}$ & 0.207 & 0.191 & 0.184 & 0.200 & 0.213 & 0.185 \\
\hline $\mathbf{K}$ & 4.02 & 4.18 & 3.67 & 5.08 & 5.41 & 7.98 \\
\hline $\mathrm{Na}$ & 59.5 & 58.3 & 58.0 & 67.8 & 64.9 & 96.4 \\
\hline Al & 0.075 & 0.162 & 0.120 & 0.169 & 0.109 & \\
\hline
\end{tabular}

CHANGE IN TUFF-PRETREATED J-13 WATER WITH TIME 
TABLE XXIV

Fe(II) ANALYSES ON USGS "STANDARD" ROCKS

\begin{tabular}{lccc} 
& \multicolumn{2}{c}{$\%$ FeO } & \\
\cline { 2 - 3 } "Standard" Rock & Los Alamos & USGS & \% Deviation \\
\hline DTS-1 (Dunite) & 7.26 & 7.23 & +0.4 \\
PCC-1 (Peridotite) & 5.11 & 5.24 & -2.5 \\
BCR-1 (Basalt) & 8.81 & 8.80 & +0.1 \\
GSP-1 (Granodiorite) & 2.23 & 2.31 & -3.5 \\
AGV-1 (Andesite) & 2.02 & 2.05 & -1.5
\end{tabular}

limit of detection is about $0.2 \mu \mathrm{g} / \mathrm{ml}\left(4 \times 10^{-6} \mathrm{M}\right)$. Correction is made for the small interference from $\mathrm{Fe}$ (III). The 4,7-diphenyl-1,10-phenanthroline reagent is more sensitive and the color developed is more stable than other phenanthrolines. Absorbance is measured at $533 \mu \mathrm{m}$ with a Hewlett-Packard model $8450 \mathrm{~A}$ UV/VIS spectrophotometer. Iron-free reagents have been prepared. D. Emission Spectrometric Analysis of Groundwaters

The Spectrometrics, Inc., 20-channel, direct current, plasma-source, emission spectrometer described in Ref. 22 is being used to analyze the extensive suite of acid-stabilized solutions saved from most of our batch sorption studies. 1,2 The samples are being analyzed for the elements on the first two cassettes described in Ref. 22 (the major ions plus representative minor elements). Selected samples are being analyzed for lanthanides using the fourth cassette.

The results will be summarized in a future report, as will the conclusions reached concerning the effects of water composition on sorption behavior.

XIII. COMPARISAY OF SORPTION RATIOS FROM BATCH, CIRCULATING-SYSTEM, AND COLUMN METHODS

The first studies of sorptive processes in this investigation were with the batch method, and use of this method has been continued because of its simplicity. It enables the relatively rapid determination of sorptive properties in scoping studies and the investigation of the effects of changes in 
many parameters. At the same time it must be recognized that the experiments may not represent in some ways the phenomena that occur in dynamic flowing systems, that is, water flowing through pores or fractures underground. Column and core experiments, which are more difficult and require much more time, are a closer approximation to true situations. The circulating system, discussed in Sec. IX, is a hybrid system that incorporates features of both batch and column methodologies.

Tables XXV, XXVI, and XXVII compare representative sorption ratios that have been obtained by the batch, circulating system, crushed-tuff column, and, in one case, whole-core column methodologies for strontium, cesium, and barium. The first three methodologies use crushed rock and may give problems in interpretation because of the freshly exposed surfaces. The batch and circulating-system procedures are similar in some ways, but the solid phase remains stationary in the circulating system and is not subject to selfgrinding. It is necessary to assume sorption-desorption equilibrium to obtain a sorption ratio from a retardation factor from column experiments. It must be emphasized that the values from the circulating system are still preliminary.

In most cases the sorption ratios are comparable and agree within a factor of 3. The values obtained by the batch method are generally greater than those from the crushed-tuff column elutions. There is no obvious pattern for a relationship between the results of the circulating-system method and the other two. However, the sorption ratios for strontium and cesium obtained by the batch system agree with those from the circulatingsystem method within a factor of 2 for all samples studied.

Although elution of ${ }^{85} \mathrm{Sr}$ from the solid YM-22 core did not exhibit a peak, the calculated sorption ratio agrees fairly well with the other methods. We have pointed out ${ }^{1,2,6}$ that simple ion-exchange equilibrium cannot fully account for the data from batch and column experiments except for the simplest cases for strontium, barium, and cesiin where sorption ratios are relatively low. This iation should be kept in mind when comparing results frow different types of dynamic and static measurements.

\section{CONCLUSIONS}

The experiments and results presented in this report were summarized in the Executive Sumnary. 
TABLE XXV

COMPARISON OF REPRESENTATIVE SORPTION RATIOS (me/g)

FOR STRONTIUM

\begin{tabular}{lccccc} 
Sample & Batch & & Circulating & Column & Core \\
\cline { 2 - 3 } YM-22 & 50 & & 23 & 30 & 20 \\
YM-54 & 84 & & 45 & 44 & \\
JA-32 & 56 & & 42 & \\
JA-37 & $300^{\mathrm{a}}$ & 394 & 106 &
\end{tabular}

${ }^{a}$ The strontium and cesium values in Table A3 of Ref. 6 should be reversed.

TABLE XXVI

COMPARISON OF REPRESENTATIVE SORPTION RATIOS (ml/g)

FOR CESIUM

$\begin{array}{lccc}\text { Sample } & \text { Batch } & \text { Circulating } & \text { Column } \\ \text { YM-22 } & 287 & 411 & 122 \\ \text { YM-54 } & 247 & 121 & 97 \\ \text { JA-37 } & 740^{\mathrm{a}} & 1770 & >560^{\mathrm{b}}\end{array}$

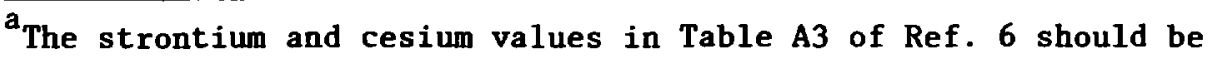
reversed.

${ }^{b}$ In progress.
}

TABLE XXVII

COMPARISON OF REPRESENTATIVE SORPTION RATIOS (ml/g)

FOR BARIUM

\begin{tabular}{lccc} 
Sample & Batch & Circulating & Column \\
\cline { 2 - 2 } & 899 & 105 & 355 \\
YM-54 & 620 & 131 & 124 \\
JA-37 & 835 & 857 &
\end{tabular}


From a geochemical viewpoint, tuff should provide a natural barrier to the migration of cations because of the excellent sorptive properties of this medium. Sorption varies with mineralogy in a reasonably consistent manner, and the best sorptive properties are found for zeolitized tuffs.

As with most geologic media, tuff exhibits relatively poor sorption for anions, for example, iodine, technetium(VII), and uranium(VI) (carbonate complex). Special consideration for retaining these elements should be given in the design of engineered barriers.

Our understanding of mechanisms of sorption and transport has increased. Isotherm experiments show that precipitation or saturation of sorption sites may occur when the sorbing element is present in high concentrations as in some release scenarios. Differences, up to a factor of 3 , have been noted in sorption ratios ubtained by static and dynamic experiments. This may be due in part to differences in solution-to-solid ratio, to self-grinding in batch experiments resulting in fine particles not present in crushed-tuff columns or in the circulating system, and to nonreversible equilibrium. Considerable progress has been made in the methodology of performing experiments with flow through whole cores of tuff.

The redox conditions in a geochemical system may affect the sorptive properties and migration of several elements with multiple oxidation states. obtaining knowledge of this parameter in the natural condition underground is necessary but difficult. Experiments for the measurement and control of the Eh in the laboratory axe in progress.

\section{ACKNOWLEDGMENTS}

The authors thank E. A. Bryant for his interest, encouragement, and reading of the manuscript. They acknowledge assiscance from the following Los Alamos personnel: M. L. Sykes, J. R. Smyth, F. H. Caporuscio, and R. G. Warren (mineralogy and petrology); D. A. Mann (technical assistance); P. A. Elder, S. Lermuseaux, and M. E. Lark (sample counting and gamma spectral analysis); and $L$. M. Mitchell (typing of the manuscript). 


\section{REFERENCES}

1. K. Wolfsberg, B. P. Bayhurst, B. M. Crowe, W. R. Daniels, B. R. Erdal, F. 0. Lawrence, A. E. Norris, and J. R. Smyth, "Sorption-Desorption Studies on Tuff. I. Initial Studies with Samples from the J-13 Drill Site, Jackass Flats, Nevada," Los Alamos National Laboratory report LA-7480-MS (1979).

2. E. N. Vine, R. D. Aguilar, B. P. Bayhurst, W. R. Daniels, S. J. DeVilliers,

B. R. Erdal, F. O. Lawrence, S. Maestas, P. Q. Oliver, J. L. Thompson, and K. Wolfsberg, "Sorptiou-Desorption Studies on Tuff. II. A Continuation of Studies with Samples from Jackass Flats, Nevada and Initial Studies with Samples from Yucca Mountain, Nevada," Los Alamos National Laboratory report LA-8110-MS (1980).

3. B. R. Erdal, W. R. Daniels, D. C. Hoffman, F. O. Lawrence, and K. Wolfsberg, "Sorption and Migration of Radionuclides in Geologic Media," in Scientific Basis for Nuclear Waste Management, Vol. 1, G. J. McCarthy, Ed. (Plenum, New York, 1979), pp. (23-426.

4. B. R. Erdal, B. P. Bayhurst, W. R. Daniels, S. J. DeVilliers, F. 0. Lawrence, E. N. Vine, and K. Wolfsberg, "Parameters Affecting Radionuclide Migration in Geologic Media," in Scientific Basis for Nuclear Waste Management, Vol. 2, C. J. M. Northrup, Jr., Ed. (Plenum, N.Y., 1980), pp. 609-616.

5. E. N. Vine, B. P. Bayhurst, W. R. Daniels, S. J. DeVilliers, B. R. Erdal, F. 0 . Lawrence, and $K$. Wolfsberg, "Radionuclide Transport in Tuff," in Scientific Basis for Nuclear Waste Management, Vol. ? (Plenum Press, New York, 1981), (in press).

6. J. K. Johnstone and K. Wolfsber3, Eds., "Evaluation of Tuff as a Medium for a Nuclear Waste Repository: Interim Status Report on the Properties of Tuff," Sandia National Laboratories report SAND80-1464 (1980).

7. B. R. Erdal, B. P. Bayhurst, B. M. Crowe, W. R. Daniels, D. C. Hoffman, F. O. Lawrence, J. R. Snyth, J. L. Thompson, and K. Wolfsberg, "Laboratory Studies of Radionuclide Transport in Geologic Media," in Underground Disposal of Radioactive Wastes, Vol. II (International Atomic Energy Agency, Vienna, 1980), pp. 367-382.

8. G. H. Heiken and M. L. Bevier, "Petrology of Tuff Units from the J-13 Drill Site, Jackass Flats, Nevada," Los Alamos National Laboratory report LA-7563-MS (1979).

9. M. L. Sykes, G. H. Heiken, and J. R. Smyth, "Mineralogy and Petrology of Tuff Units from the UE25a-1 Drill Site, Yucca Mountain, Nevada," Los Alamos National Laboratory report LA-8139-MS (1979).

10. K. Wolfsberg and B. R. Erdal, Eds., "Research and Developwent Re iated to the Hevada Nuclear Waste Storage Investigations, October 1 - Decerber 31 , 1980," Los Alamos National Laboratory report LA-8739-PR (1981). 
11. H. C. Classen, "Water Quality and Physical Characteristics of Nevada Test Site Water-Supply Wel1s," USGS report USGS-474-158 (1973).

12. K. Wolfsberg, B. R. Erdal, and J. R. Smyth, Eds., "Research and Development Related to the Nevada Nuclear Waste Storage Investigations, April 1 June 30, 1980," Los Alamos National Laboratory report LA-8471-PR $(1980)$.

13. B. R. Erda1, R. D. Aguilar, B. P. Bayhurst, W. R. Daniels, C. J. Duffy, F. O. Lawrence, S. Maestas, P. Q. Oliver, and K. Wolfsberg, "SorptionDesorption Studies on Granite," Los Alamos National Laboratory report LA-7456-MS (1979).

14. W. R. Daniels, Ed., "Laboratory Studies of Radionuclide Distributions Between Selected Groundwaters and Geologic Media, October 1, 1979-September $30,1980, "$ Los Alamos National Laboratory report LA-8586-PR (1981).

15. T. Vermeulen, G. Klein, and N. Hiester, "Adsorption and Ion Exchange," in Chemical Engineers' Handbook, R. H. Perry and C. H. Chilton, Eds. (New York, McGraw-Hill, 5th Ed., New York, 1973), section 16.

16. W. Stumm and J. J. Morgan, Aquatic Chemistry (Wiley-Interscience, New York, 1970), Pp. 300-382.

17. J. M Ottaway, "Oxidation Reduction Indicators of $E^{\prime}<0.76$ Volt," in Indicators, E. Bishop, Ed. (Pergamon Press, Oxford, 1972) p. 469.

18. J. C. Harrar, "Techniques, Apparatus, and Analytical Application of Controlled-Potential Coulometry," in Electroanalytical Chemistry, Vol. 8, A. J. Bard, Ed. (Marcel Dekker, New York, 1975) p. 1.

19. D. Rai, R. J. Serne, D. A. Moore, and R. W. Stromatt, "Electron Transfer Method of Controlling Eh during Adsorption of Multivalent Elements by Geologic Media," Battelle Pacific Northwest Laboratories report PNL-SA6766 (1978).

20. S. Banerjee, "Direct Determination of Ferrous Iron in Silicate Rocks and Minerals by Iodine Monochloride," Anal. Chem. 46, 782 (1974).

21. G. F. Lee and W. Stum, "Determination of Ferrous Iron in the Presence of Ferric Iron with Bathophenanthroline," J. AWWA 52, 1567 (1960).

22. B. R. Erda1, Ed., "Laboratory Studies of Radionuclide Distributions Between Selected Groundwaters and Geologic Media, Annual Report, October 1, 1978 - September 30, 1979," Los Alamos National Laboratory report LA-8088-PR (1979). 